\title{
The evolution of biomass-burning aerosol size distributions due to coagulation: dependence on fire and meteorological details and parameterization
}

\author{
Kimiko M. Sakamoto ${ }^{1}$, James R. Laing ${ }^{2}$, Robin G. Stevens ${ }^{3}$, Daniel A. Jaffe ${ }^{2,4}$, and Jeffrey R. Pierce ${ }^{1,5}$ \\ ${ }^{1}$ Department of Atmospheric Science, Colorado State University, Fort Collins, CO, USA \\ ${ }^{2}$ School of Science and Technology, University of Washington-Bothell, Bothell, WA, USA \\ ${ }^{3}$ School of Earth and Environment, University of Leeds, Leeds, UK \\ ${ }^{4}$ Department of Atmospheric Science, University of Washington, Seattle, WA, USA \\ ${ }^{5}$ Department of Physics and Atmospheric Science, Dalhousie University, Halifax, NS, Canada
}

Correspondence to: Jeffrey R. Pierce (jeffrey.pierce@ colostate.edu)

Received: 5 January 2016 - Published in Atmos. Chem. Phys. Discuss.: 25 February 2016

Revised: 2 June 2016 - Accepted: 6 June 2016 - Published: 24 June 2016

\begin{abstract}
Biomass-burning aerosols have a significant effect on global and regional aerosol climate forcings. To model the magnitude of these effects accurately requires knowledge of the size distribution of the emitted and evolving aerosol particles. Current biomass-burning inventories do not include size distributions, and global and regional models generally assume a fixed size distribution from all biomass-burning emissions. However, biomass-burning size distributions evolve in the plume due to coagulation and net organic aerosol (OA) evaporation or formation, and the plume processes occur on spacial scales smaller than global/regional-model grid boxes. The extent of this size-distribution evolution is dependent on a variety of factors relating to the emission source and atmospheric conditions. Therefore, accurately accounting for biomass-burning aerosol size in global models requires an effective aerosol size distribution that accounts for this subgrid evolution and can be derived from available emissioninventory and meteorological parameters.

In this paper, we perform a detailed investigation of the effects of coagulation on the aerosol size distribution in biomass-burning plumes. We compare the effect of coagulation to that of OA evaporation and formation. We develop coagulation-only parameterizations for effective biomassburning size distributions using the SAM-TOMAS largeeddy simulation plume model. For the most-sophisticated parameterization, we use the Gaussian Emulation Machine for Sensitivity Analysis (GEM-SA) to build a parameter-
\end{abstract}

ization of the aged size distribution based on the SAMTOMAS output and seven inputs: emission median dry diameter, emission distribution modal width, mass emissions flux, fire area, mean boundary-layer wind speed, plume mixing depth, and time/distance since emission. This parameterization was tested against an independent set of SAMTOMAS simulations and yields $R^{2}$ values of 0.83 and 0.89 for $D_{\mathrm{pm}}$ and modal width, respectively. The size distribution is particularly sensitive to the mass emissions flux, fire area, wind speed, and time, and we provide simplified fits of the aged size distribution to just these input variables. The simplified fits were tested against 11 aged biomass-burning size distributions observed at the Mt. Bachelor Observatory in August 2015. The simple fits captured over half of the variability in observed $D_{\mathrm{pm}}$ and modal width even though the freshly emitted $D_{\mathrm{pm}}$ and modal widths were unknown. These fits may be used in global and regional aerosol models. Finally, we show that coagulation generally leads to greater changes in the particle size distribution than OA evaporation/formation does, using estimates of OA production/loss from the literature. 


\section{Introduction}

\section{Biomass-burning aerosols}

Biomass burning (including wildfires, prescribed fires, and agricultural fires) releases significant amounts of gas- and particle-phase species to the atmosphere (Andreae and Merlet, 2001; Reid et al., 2005). The particle-phase emissions are composed primarily of a mixture of organic aerosol (OA) and black carbon (BC) with some inorganic species (e.g., potassium), and the ratios of these species depend on the source fire conditions (Capes et al., 2008; Carrico et al., 2010; $\mathrm{Cu}-$ bison et al., 2011; Hecobian et al., 2011; Hennigan et al., 2011; Reid et al., 2005). These aerosols affect the global radiation budget through the indirect and direct aerosol effects (Boucher et al., 2013). The smoke particles themselves are able to act as cloud condensation nuclei (CCN) and increase cloud albedo and lifetime (indirect aerosol effect; Lee et al., 2013; Pierce et al., 2007; Spracklen et al., 2011) as well as scattering/absorbing incoming solar-radiation directly (direct aerosol effect; Alonso-Blanco et al., 2014; Boucher et al., 2013; Haywood and Boucher, 2000; Jacobson, 2001).

Particle size has a significant effect on the magnitude of both the direct and indirect aerosol effects (Lee et al., 2013; Seinfeld and Pandis, 2006; Spracklen et al., 2011). The composition and diameter of the particles affect their absorption/scattering efficiencies, which dictate the amount of solar radiation absorbed/scattered per emitted mass of particles (Seinfeld and Pandis, 2006). Particle diameter and hygroscopicity determine the particles' ability to act as $\mathrm{CCN}$ and influence cloud processes, and the total number of emitted particles increases with decreased particle size when total mass emissions are fixed. Spracklen et al. (2011) found that a reduction by a factor of 2 in particle size for all carbonaceous aerosols (for a fixed total aerosol mass) resulted in a $300 \%$ increase in the cloud albedo indirect effect globally, as more particles were available to act as CCN. Lee et al. (2013) determined that $\mathrm{CCN}$ concentrations in the GLOMAP model were very sensitive to uncertainties in biomass-burning emission diameter on both the regional and global scale (its attributable CCN uncertainty ranked third of 28 factors tested globally). Therefore, to ascertain the role of biomass-burning aerosols in climate forcings accurately, biomass-burning size distributions must be well represented in aerosol-climate models.

Size distributions are subject to physical and chemical processing in the plume. The formation of secondary organic aerosol (SOA) has been observed in lab studies of biomassburning aerosol (Cubison et al., 2011; Grieshop et al., 2009; Hennigan et al., 2011; Heringa et al., 2011; Ortega et al., 2013) and in field campaigns (DeCarlo et al., 2010; Lee et al., 2008; Reid and Hobbs, 1998; Yokelson et al., 2009). This SOA can condense onto existing particles causing growth of the aerosol size distribution. It can also spur new-particle formation in biomass-burning plumes as has been observed in lab studies (Hennigan et al., 2012) and field campaign analyses (Vakkari et al., 2014). Conversely, recent lab and field studies have characterized primary organic aerosol as semivolatile, with plume dilution allowing the evaporation of organic aerosol from particles (Huffman et al., 2009; Cubison et al., 2011; May et al., 2013, 2015; Jolleys et al., 2015). The cumulative net effects of OA production/loss within biomassburning plumes have been found to be highly variable from fire to fire (Akagi et al., 2012; Hennigan et al., 2011).

Coagulation is also important for size-distribution evolution as it reduces particle number and shifts the distribution to larger sizes. Coagulation rates are proportional to the square of the particle number concentration (all else remaining fixed), so the high number concentrations in biomassburning plumes relative to background can lead to rapid coagulational growth of the size distribution. The coagulation rate is therefore also affected by the rate of plume dilution (through a reduction in number concentrations, or $N$ ), itself a function of plume size and meteorological conditions. The rate and magnitude of the aerosol growth caused by these combined processes are functions of aging time, emission source characteristics, aerosol properties at emission, and atmospheric conditions.

These condensation/evaporation and coagulation aging processes affect both the composition and size of the aerosol size distribution - both properties that influence the extent to which smoke particles affect climate. While fresh smoke is generally composed of fine particles between 20 and $60 \mathrm{~nm}$ in diameter (Levin et al., 2010), condensation and coagulation cause rapid aerosol growth to larger sizes (over $100 \mathrm{~nm}$ ) on timescales of often less than $24 \mathrm{~h}$ (Janhäll et al., 2010). However, Janhäll et al. (2010) found the observed geometric mean diameter of aged biomass-burning particles varied between 170 and $300 \mathrm{~nm}$, with geometric standard deviations (hereafter referred to as "modal width") between 1.3 and 1.7 with significant dependence on fuel type and modified combustion efficiency. It is currently unclear to what extent these factors and others drive the variability in aged size distributions.

As stated earlier, an accurate representation of aged biomass-burning aerosol size is necessary for predictions of aerosol climate effects in regional and global models (Lee et al., 2013). Current wildfire inventories are mass based (neglecting aerosol size data), and thus regional and global models used for aerosol-climate effects generally specify fixed, "aged" size distributions that do not account for sub-grid processing of the emitted particles (Reid et al., 2009; van der Werf et al., 2010; Wiedinmyer et al., 2011). Any variability in the biomass-burning size distribution due to fire or emissions characteristics and meteorology is not accounted for, nor is it clear what the best "aged" size distribution to use is in these models.

In this paper, we perform a detailed investigation of coagulation in biomass-burning plumes and compare to the effects of OA evaporation and formation. We investigate the 
factors that influence coagulational growth of the particles in the plume. These factors include fire area, particle-emissions mass flux, particle-emissions size, and meteorological conditions. We create parameterizations of varying degrees of complexity for median dry diameter $\left(D_{\mathrm{pm}}\right)$ and lognormal modal width $(\sigma)$ of the aged biomass-burning size distributions as a function of these input parameters, based on detailed numerical simulations using a large-eddy simulation (LES) model with embedded aerosol microphysics (SAMTOMAS; System for Atmospheric Modelling with the online aerosol microphysics module, TwO Moment Aerosol Sectional). Finally, we compare the effect of coagulation on the aerosol size distribution to that of OA production/evaporation.

We describe the parameterization building process, including the use of a Gaussian emulator, in Sect. 2. A discussion of input and output ranges, processing, and constraints of the parameters we have chosen is provided in Sect. 2.1. We discuss the SAM-TOMAS model and the emulation process in Sects. 2.2-2.3. Sections 3.1-3.2 contain the results of the SAM-TOMAS model and the emulator. We discuss emulator sensitivities to the inputs in Sect. 3.3 and present a series of simplified fit equations for the effective size distributions in Sect. 3.4. We discuss the effects of potential OA production/loss on our size-distribution estimates in Sect. 3.5. The simplified-fit equations are tested against biomass-burning plumes observed at the Mt. Bachelor Observatory in Sect. 3.6. Finally, we conclude in Sect. 4, including future plans for testing the parameterization and known existing limitations.

\section{Methods}

Figure 1 provides an overview of our methods that will be described in detail in the subsections below. In short, we used an LES model, the SAM-TOMAS (Khairoutdinov and Randall, 2003; Adams and Seinfeld, 2002; Stevens et al., 2012), to simulate the evolution of the biomass-burning aerosol size distribution by coagulation across a wide range of emission and meteorological conditions. We used the SAM-TOMAS size distributions to build parameterizations to predict aged $D_{\text {pm }}$ and $\sigma$ using (1) a statistical emulator of the SAMTOMAS model itself and (2) simplified fits to the SAMTOMAS output data. The statistical emulator was built by the Gaussian Emulation Machine for Sensitivity Analysis (GEM-SA), and we used the emulator and SAM-TOMAS data to determine the relative importance of various inputs to shaping the aged size distribution.

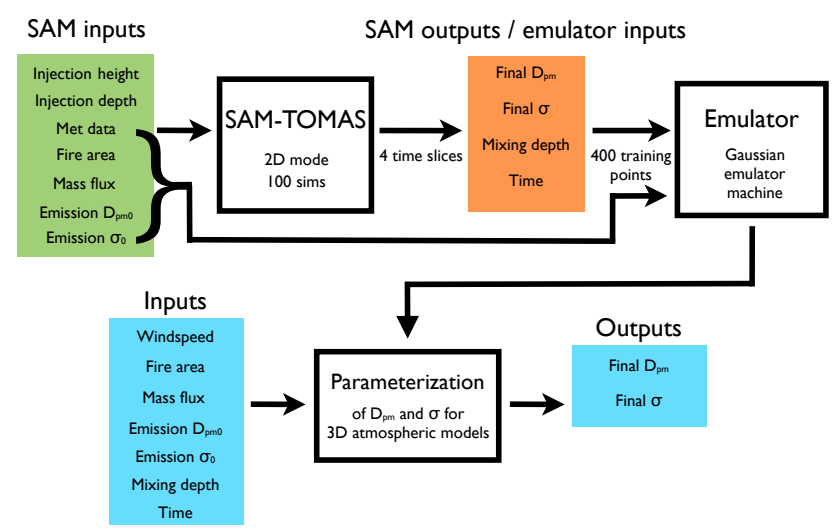

Figure 1. Schematic of the methods in this paper.

\subsection{Investigated factors that may lead to variability in aged size distributions}

We investigated seven parameters that may affect the aging of the biomass-burning aerosol size distribution. These can be divided into those representing the initial lognormalmode size parameters $\left(D_{\mathrm{pm} 0}, \sigma_{0}\right)$, fire conditions (mass flux, fire area), atmospheric conditions (wind speed, plume mixing depth), and time. Each of these parameters is generally available in large-scale aerosol models, which means a parameterization for aged biomass-burning size distributions based on these parameters may be used in these models. Table 1 lists these input parameters and the ranges of values tested in this work.

We assumed that the initial size distributions were a single lognormal mode (described by dry median diameter, $D_{\mathrm{pm}}$, and modal width, $\sigma$ ), which is sufficient when representing both fresh and aged observed biomass-burning size distributions (Capes et al., 2008; Janhäll et al., 2010; Levin et al., 2010; Sakamoto et al., 2015). The initial size-distribution parameters specify the median dry diameter $\left(D_{\mathrm{pm} 0}\right)$ and modal width $\left(\sigma_{0}\right)$ of the freshly emitted aerosol distribution. We varied these parameters between 20 and $100 \mathrm{~nm}$ for $D_{\mathrm{pm} 0}$ and 1.2 and 2.4 for $\sigma_{0}$. The large ranges are due to variability in combustion efficiency and fuel-type factors as seen in lab and observational studies (Janhäll et al., 2010; Levin et al., 2010).

Fire area, mass flux, wind speed, and aerosol mixing depth (hereafter referred to as "mixing depth"; the vertical extent of the aerosol plume) all affect the aerosol $N$ within the plume, which in turn affects the coagulation rate (proportional to $N^{2}$ ). In our simulations, we constrained mass flux to $2 \times 10^{-8}-5 \times 10^{-6} \mathrm{~kg} \mathrm{~m}^{-2} \mathrm{~s}^{-1}$ using approximate maximum and minimum values of summed black carbon and organic carbon flux $(\mathrm{BC}+\mathrm{OC})$ found in the Global Fire Emissions Database v. 3 (GFED3; van der Werf et al., 2010; available from http://www.globalfiredata.org). Fire area ranged from 1 to $49 \mathrm{~km}^{2}$ (simulated as a square), which was found to represent the range of fire sizes in GFED3. Boundary-layer 
Table 1. Parameter ranges for each of the seven input parameters investigated in this study.

\begin{tabular}{lllrr}
\hline Parameter & Description & Units & Min. value & Max. value \\
\hline$D_{\mathrm{pm} 0}$ & Emission median dry diameter & $\mathrm{nm}$ & 20 & 100 \\
$\sigma_{0}$ & Emission modal width & - & 1.2 & 2.4 \\
Mass flux & Emission mass flux from fire & $\mathrm{kg} \mathrm{m}^{-2} \mathrm{~s}^{-1}$ & $2 \times 10^{-8}$ & $5 \times 10^{-6}$ \\
Fire area & Square fire emissions area & $\mathrm{km}^{2}$ & 1 & 49 \\
Wind speed & Mean boundary-layer wind speed & $\mathrm{m} \mathrm{s}^{-1}$ & 2 & 20 \\
Mixing depth & Mixing depth of aerosol layer & $\mathrm{m}$ & 150 & 2500 \\
Time & Time since emission & min & 0 & 300 \\
\hline
\end{tabular}

wind speed varied between 2 and $20 \mathrm{~m} \mathrm{~s}^{-1}$ and was based on ranges in the National Center for Environmental Prediction (NCEP) North American Regional Reanalysis (NARR) meteorology (Mesinger et al., 2006) during the fire season (specifically July 2010). Mixing depth had a range of 150$2500 \mathrm{~m}$ (based on SAM-TOMAS output; see Sect. 2.2).

The aging time was the final input parameter, and we used $5 \mathrm{~h}$ (300 min) as an upper time bound due to this being a typical timescale for transport across large global model grid boxes.

\subsection{The SAM-TOMAS model}

We used the SAM-TOMAS model to simulate the evolution of biomass-burning aerosol size distributions due to coagulation across the range of input parameters described above. SAM (Khairoutdinov and Randall, 2003) is a dynamical LES model, which has previously been used to model emissions plumes (Lonsdale et al., 2012; Stevens et al., 2012; Stevens and Pierce, 2013). We ran the model in Lagrangian 2-D mode (Stevens and Pierce, 2013), in which a wall oriented normal to the mean boundary-layer wind moves at the mean boundary-layer wind speed. This moving wall tracks the radial dispersion of a plume as it travels downwind (Fig. 2). This 2-D mode is computationally efficient compared to the full 3-D model with minor differences due to axial plume symmetry (Stevens and Pierce, 2013).

The size distributions of the aerosol particles in SAM were simulated using the TOMAS (Adams and Seinfeld, 2002) microphysical scheme embedded into SAM. The algorithm simulated the size distribution across 13 logarithmically spaced size bins spanning $3 \mathrm{~nm}^{-1} \mu \mathrm{m}$ with 2 additional bins spanning $1-10 \mu \mathrm{m}$. The aerosol size distribution was tracked via two independent moments for each bin of the size distribution (mass and number). TOMAS calculated coagulation explicitly in each grid cell assuming a Brownian diffusion kernel (Seinfeld and Pandis, 2006). Our SAMTOMAS simulations included only coagulation, and particles were assumed to be a single species (no differentiating between BC and OA). The SAM-TOMAS model had previously been tested against observations in Stevens et al. (2012) and Lonsdale et al. (2012) for power plant plumes.

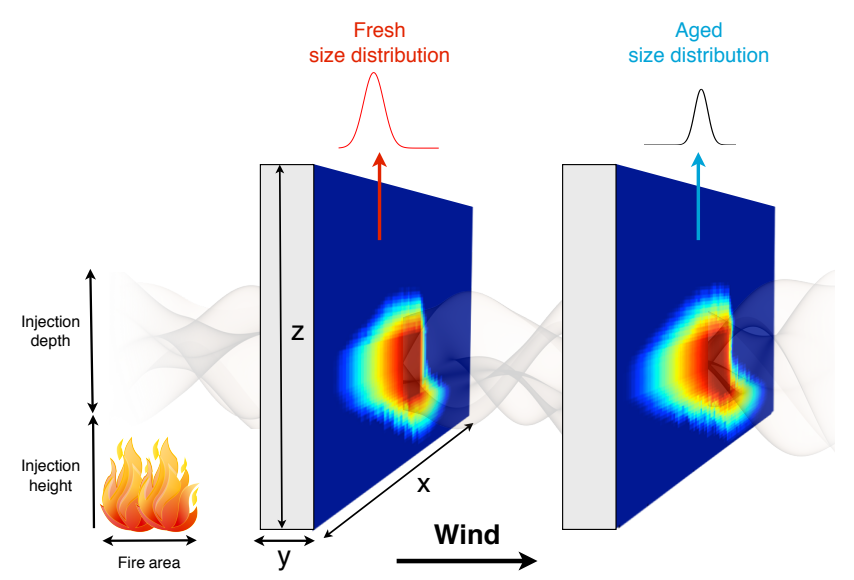

Figure 2. Schematic of a 2-D SAM-TOMAS plume simulation.

We set background aerosol concentrations to zero as the biomass-burning aerosol concentrations emitted into SAMTOMAS were orders of magnitude larger than those present in a remote background location, and as such the lack of background aerosol would have had an insignificant effect on the rate of in-plume coagulational processing. In cases where the plume dilutes to concentrations similar to the ambient background, subgrid-plume coagulation schemes are no longer necessary, and grid-resolved coagulation will properly account for coagulation. The biomass-burning aerosol was assumed to have a constant density of $1400 \mathrm{~kg} \mathrm{~m}^{-3}$ as primarily a mix of organic compounds; thus we do not consider how changes in BC/OA composition may affect density and coagulation rates. The hygroscopicity of the aerosol particles was set to zero, allowing no water uptake. This assumption is not true of real world biomass-burning aerosol and has been characterized in other works that find hygroscopicities of fresh $(\kappa=0.02-0.8$; Petters et al., 2009) and aged smoke ( $\kappa=0.1-0.3$; Engelhart et al., 2012) with a strong dependence on fuel type. In terms of their effect on the size distribution, a constant $\kappa$ across all particle sizes has the simple effect of increasing the effective diameter of the particles via water uptake by a scalar factor. This initial increase should only have a relatively minor effect on the final dry $D_{\mathrm{pm}}$ or $\sigma$ of the plume after coagulational processing as the mean 
coagulation rates are relatively insensitive to the size shifting of a particle population (Seinfeld and Pandis, 2006; Stuart et al., 2013).

We ran 100 SAM-TOMAS simulations at $500 \mathrm{~m} \times 500 \mathrm{~m}$ horizontal resolution (total cross-wind ( $y$ direction) horizontal extent $=100 \mathrm{~km}$ ) and constant $40 \mathrm{~m}$ vertical resolution (total vertical extent $=4 \mathrm{~km}$ ). This resolution accommodated the chosen plume parameters (see Sect. 2.1). The model was run with a master timestep of $2 \mathrm{~s}$ (varied internally for accuracy in the coagulation calculation) for a duration of 5 model hours $(300 \mathrm{~min})$. The output from each SAM-TOMAS simulation was recorded at four different times (400 total time slices across 100 simulations) as the plume progressed along the with-wind ( $x$ direction) axis.

The seven inputs to the SAM-TOMAS model were constrained to capture a range of biomass-burning characteristics in realistic scenarios and are summarized in Table 2. The ranges of values used for $D_{\mathrm{pm} 0}, \sigma_{0}$, fire area, and mass flux are the same as those listed in Table 1 . The meteorological fields were supplied by NCEP reanalysis meteorology from over North America (land only, lat: $30-70^{\circ} \mathrm{N}$, long: $70-135^{\circ} \mathrm{W}$ ) during the July 2010 fire season. The SAMTOMAS wall speed was set equal to the mean boundarylayer wind speed from NCEP. We filtered these inputs by requiring wind speed $>2 \mathrm{~m} \mathrm{~s}^{-1}$ to eliminate stagnation situations over the source. The injection height (lower bound) and injection depth of the aerosol were specified at between 50 and 1500 and 500 and $2000 \mathrm{~m}$, respectively. No emission injection parameterization (e.g., Freitas et al., 2007) was used as we were only trying to capture a range of mixing depths for our aging calculation, and the absolute height was relatively unimportant. All the SAM-TOMAS simulation inputs were chosen using semi-random Latin hypercube sampling across the ranges listed above (Lee et al., 2012). The results of the full SAM-TOMAS simulation set are summarized in Sect. 3.1.

We calculated the time-dependent mixing depth of the plume from vertical profiles averaged horizontally across the entire simulation wall at each time slice. Figure 3 shows a sample of two vertical profiles from different SAM-TOMAS simulations. The mixing depth was defined as the range of altitudes where the aerosol mass was greater than half of the peak aerosol mass:

mixing depth $=\Delta_{\text {alt }} 50 \%$ peak aerosol mass .

In cases where the plume mixed down to the ground, the lower altitude bound was defined as $0 \mathrm{~m}$. Runs with mixing depths greater than $2500 \mathrm{~m}$ were excluded to ensure that the plume did not reach the model top. In addition to mixing depth, $D_{\mathrm{pm}}$ and $\sigma$ were calculated for each of the SAM-TOMAS time slices from the first and third integrated moments of the size distribution as detailed by Whitby et al. (1991).

We do not address new-particle formation in biomassburning plumes in this work. In plumes where new-particle

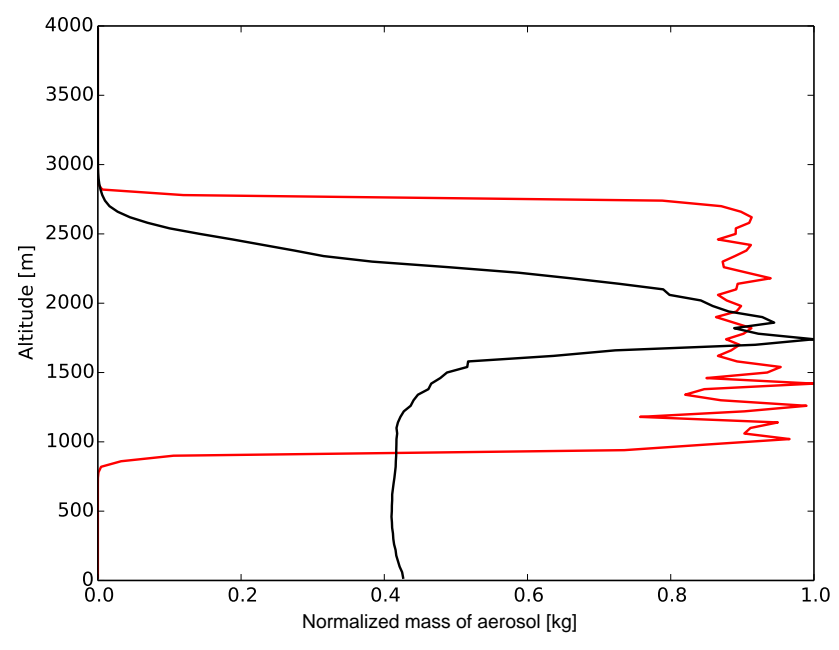

Figure 3. Final vertical profiles for two representative SAMTOMAS simulations after $4 \mathrm{~h}$, normalized to individual aerosol load and averaged horizontally across the domain. The black profile shows a simulation where the aerosol mixed through the boundary layer to the ground with some aerosol still trapped in a stable emission layer, while the red profile shows a simulation where the aerosol plume is still stable at the emission injection layer.

formation in biomass-burning plumes occurs, our parameterizations will underestimate the number of particles and overestimate the mean diameter of the plume particles.

\subsection{Emulation of the SAM-TOMAS output}

As running the full SAM-TOMAS model is too computationally expensive for implementation in global aerosol models, we built an offline emulator of the model for use as a parameterization in these global models. We created the emulator using the GEM-SA developed by the Centre for Terrestrial Carbon Dynamics (available at http://www.tonyohagan. co.uk/academic/GEM/index.html). The GEM-SA software uses a Gaussian process to design a SAM-TOMAS simulator (the emulator) based on the behavior of the known SAM-TOMAS inputs and outputs (the training data). A complete description of GEM-SA statistics and assumptions can be found in Kennedy and O'Hagan (2001) and Kennedy et al. (2008). A description of its application as an estimator in atmospheric-aerosol modeling can be found in Lee et al. (2011). This software was previously used in sensitivity studies in atmospheric-aerosol (Lee et al., 2011, 2012) and vegetation models (Kennedy et al., 2008).

We used 400 data points from the set of 100 SAMTOMAS simulations to train the emulator. GEM-SA assumes that the outputs are a continuous and differentiable function of the inputs to statistically emulate the model and estimate the SAM-TOMAS output ( $D_{\mathrm{pm}}$ and $\sigma$ ). We used a new set of completed SAM-TOMAS simulations (624 non-training data points) to test our GEM-SA parameterization for accuracy relative to SAM-TOMAS (see Sects. 3.2-3.3). 
Table 2. Parameter ranges for inputs to the SAM-TOMAS model.

\begin{tabular}{|c|c|c|c|c|}
\hline Parameter & Description & Units & Min. value & Max. value \\
\hline Date & Req. for met. field selection & $8 \mathrm{~h}$ & 1 July 2010 & 31 July 2010 \\
\hline Latitude & & ${ }^{\circ} \mathrm{N}$ & 30 & 70 \\
\hline Longitude & & ${ }^{\circ} \mathrm{W}$ & 70 & 135 \\
\hline$D_{\mathrm{pm} 0}$ & Emission median dry diameter & $\mathrm{nm}$ & 20 & 100 \\
\hline$\sigma_{0}$ & Emission modal width & - & 1.2 & 2.4 \\
\hline Mass flux & Emission mass flux from fire & $\mathrm{kg} \mathrm{m}^{-2} \mathrm{~s}^{-1}$ & $2 \times 10^{-8}$ & $5 \times 10^{-6}$ \\
\hline Fire area & Square fire emissions area & $\mathrm{km}^{2}$ & 1 & 49 \\
\hline Injection height & Lower plume injection bound & $\mathrm{m}$ & 50 & 150 \\
\hline Injection depth & Depth of plume at emission & $\mathrm{m}$ & 500 & 2000 \\
\hline
\end{tabular}

The GEM-SA parameterization requires seven input parameters $\left(D_{\mathrm{pm} 0}, \sigma_{0}\right.$, mass flux, fire area, wind speed, mixing depth and time) and generates predicted aged $D_{\mathrm{pm}}$ and $\sigma$ as outputs. These estimated $D_{\mathrm{pm}}$ and $\sigma$ describe an aged lognormal aerosol mode incorporating the sub-grid scale coagulation taking place inside concentrated biomass-burning plumes and can be used in global/regional models. We have made the GEM-SA parameterization (emulator Fortran subroutine and input files) available as Supplement.

\section{Results}

\subsection{SAM-TOMAS simulation output}

Figure 4 shows the $D_{\mathrm{pm}}$ (panels a and c) and $\sigma$ (panels b and d) as a function of distance for each of the 100 SAM-TOMAS simulations used to train the emulator (Sect. 3.2). The influence of several factors (the distance from the source, emissions mass flux, and fire area) on the final aerosol size distributions is apparent in the output of SAM-TOMAS simulations. Panels $\mathrm{a}$ and $\mathrm{b}$ are colored by the emissions mass flux, whereas panels $\mathrm{c}$ and $\mathrm{d}$ are colored by $\mathrm{d} M / \mathrm{d} x \mathrm{~d} z\left(\mathrm{~kg} \mathrm{~m}^{-2}\right.$; the amount of aerosol mass in an infinitesimally thin slice of air perpendicular to the direction of the wind, i.e., mass flux · fire area/wind speed/mixing depth). All simulations showed $D_{\mathrm{pm}}$ increasing with distance as coagulation progressed in each plume. The coloring in panel a shows that $D_{\text {pm }}$ generally increases more rapidly and to higher values with higher emission fluxes. However, panel c shows that $\mathrm{d} M / \mathrm{d} x \mathrm{~d} z$ appears to be a better predictor for the increase of $D_{\mathrm{pm}}$ with distance than the emissions flux, and the distance and $\mathrm{d} M / \mathrm{d} x \mathrm{~d} z$ capture much of the variability in $D_{\mathrm{pm}}$.

Panels $\mathrm{b}$ and $\mathrm{d}$ show that $\sigma$ tends to converge with distance as simulations with large initial $\sigma$ generally decrease with distance more rapidly than simulations with smaller initial $\sigma$. This convergence happens slowly relative to the times simulated, so the initial $\sigma$ have a strong influence even at $200 \mathrm{~km}$. The colors and panels $\mathrm{b}$ and d show that $\sigma$ in high emission-flux and $\mathrm{d} M / \mathrm{d} x \mathrm{~d} z$ cases converge more rapidly than low-emissions cases. However, as opposed to
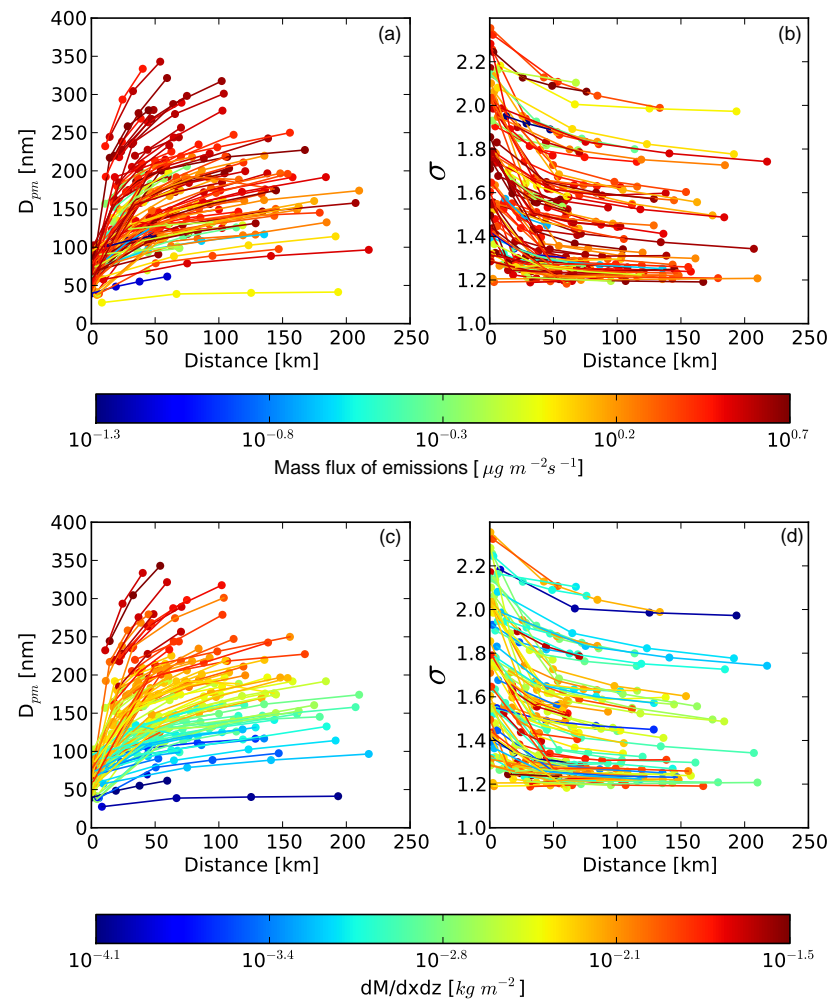

Figure 4. Wire plots showing size-distribution changes across individual SAM-TOMAS simulations colored by emission mass flux (a, b) and $\mathrm{d} M / \mathrm{d} x \mathrm{~d} z(\mathbf{c}, \mathbf{d})$ for $D_{\mathrm{pm}}(\mathbf{a}, \mathbf{c})$ and $\sigma(\mathbf{b}, \mathbf{d})$.

the 1.32 modal-width asymptote in the limit of infinite coagulation found by Lee (1983), the SAM-TOMAS simulations converge to a limit of 1.2-1.25. This is likely due to the sizedistribution bin spacing in the SAM-TOMAS model, where modal widths $<1.32$ are smaller than a single TOMAS size bin width, which results in less accurate fits of $\sigma$ for smaller $\sigma$ values.

Figure 5 is a scatterplot of $\sigma$ vs. $D_{\text {pm }}$ for each point seen in Fig. 4, excepting those at distances less than $25 \mathrm{~km}$ (points close to the emissions source have been removed). The points are colored by $\mathrm{d} M / \mathrm{d} x \mathrm{~d} z$. Thus, Fig. 5 shows the results of 


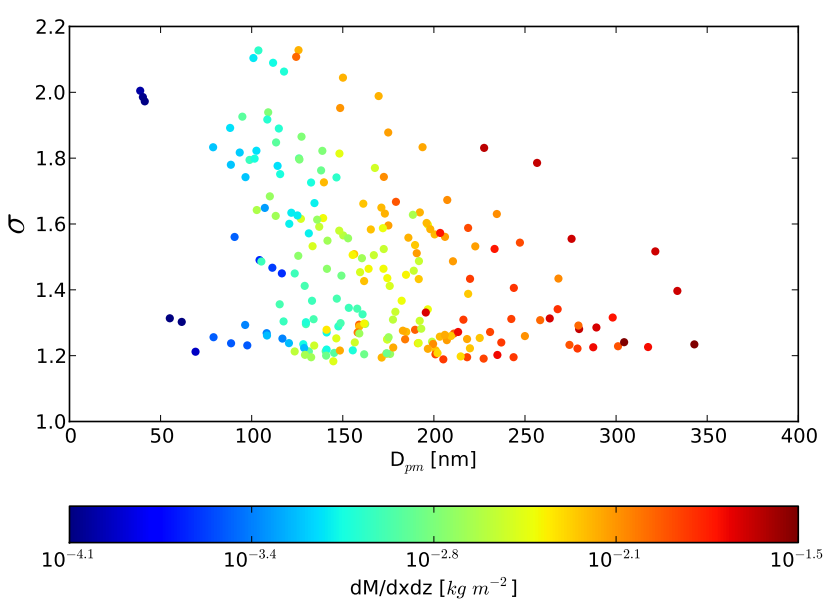

Figure 5. Scatterplot showing the relationships between final modal width $(\sigma)$, final $D_{\mathrm{pm}}$, and $\mathrm{d} M / \mathrm{d} x \mathrm{~d} z$ for each of the SAM-TOMAS simulation slices at distances greater than $25 \mathrm{~km}$ from the fire.

Fig. $4 \mathrm{c}$ and $\mathrm{d}$ together but removes the distance information. At these distances over $25 \mathrm{~km}, D_{\text {pm }}$ is relatively well constrained by $\mathrm{d} M / \mathrm{d} x \mathrm{~d} z$ alone, showing that the mean growth by coagulation is strongly influenced by the mass of particles in the slice of air. In contrast, $\sigma$ is unconstrained at low values of $\mathrm{d} M / \mathrm{d} x \mathrm{~d} z$ but more constrained towards 1.2-1.4 at high values of $\mathrm{d} M / \mathrm{d} x \mathrm{~d} z$. At high $\mathrm{d} M / \mathrm{d} x \mathrm{~d} z$ values, the convergence towards the steady-state $\sigma$ proceeds much more rapidly than at low $\mathrm{d} M / \mathrm{d} x \mathrm{~d} z$ as also shown in Fig. $4 \mathrm{~d}$.

These SAM-TOMAS results show that $\mathrm{d} M / \mathrm{d} x \mathrm{~d} z$ is a powerful determinant of aged biomass-burning size. In these tests, we also explored the suitability of $\mathrm{d} M / \mathrm{d} x$ (mass flux · fire area/wind speed) and $\mathrm{d} M / \mathrm{d} V$ (initial mass concentration). Large mixing depths dilute particle concentrations and reduce coagulation, so we expected that $\mathrm{d} M / \mathrm{d} x \mathrm{~d} z$ may be a better predictor of biomass-burning size-distribution aging than $\mathrm{d} M / \mathrm{d} x$. However, Figs. 4 and 5 did not look qualitatively different when using $\mathrm{d} M / \mathrm{d} x$ or $\mathrm{d} M / \mathrm{d} V$. A comparison of $\mathrm{d} M / \mathrm{d} x$ vs. $\mathrm{d} M / \mathrm{d} x \mathrm{~d} z$ vs. $\mathrm{d} M / \mathrm{d} V$ in predicting final size-distribution attributes is further discussed in Sect. 3.4. We quantitatively evaluate the fidelity of $\mathrm{d} M / \mathrm{d} x$ and $\mathrm{d} M / \mathrm{d} x \mathrm{~d} z$ as proxies for biomass-burning sizedistribution aging in Sect. 3.4. In the following two subsections, we use the emulator to determine the contribution of the individual inputs to the changes in simulated $D_{\mathrm{pm}}$ and $\sigma$.

\subsection{Model parameterization evaluation}

We tested the GEM-SA-derived emulator parameterization against additional SAM-TOMAS model runs that were not used in the fitting of the parameterization, and we show the results in Fig. 6. We use 624 additional SAM-TOMASsimulated data points that were not used for GEM-SA training in this evaluation. The emulator parameterizationpredicted outputs corresponding to these data points for
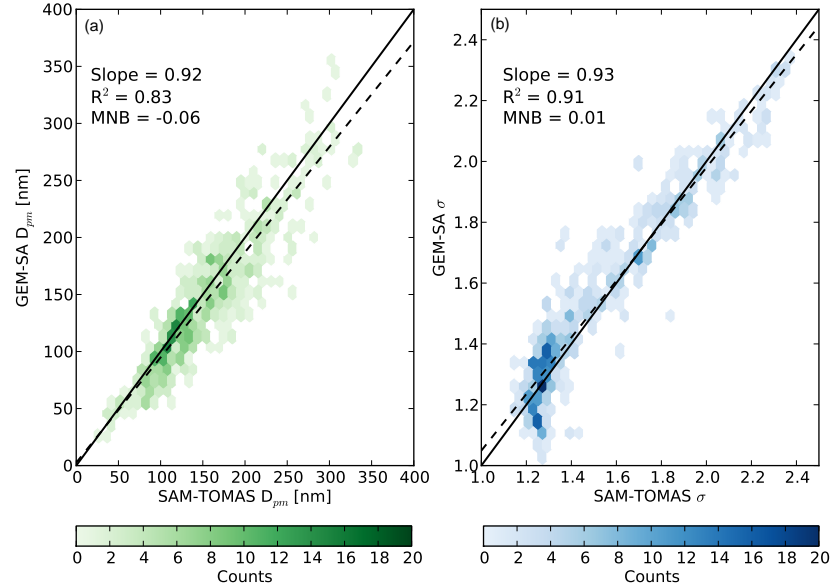

Figure 6. One-to-one plots showing GEM-SA emulator vs. SAMTOMAS for 624 non-training simulation slices for (a) final $D_{\mathrm{pm}}$ and (b) final modal width, $\sigma$. The black line is the one-to-one line. The dashed black line is the line of best fit.

$D_{\mathrm{pm}}$ and $\sigma$ are plotted against the SAM-TOMAS $D_{\mathrm{pm}}$ and $\sigma$. Predicted $D_{\text {pm }}$ has an $R^{2}$ value of 0.83 with a slope of 0.92. Larger absolute errors in $D_{\mathrm{pm}}$ are found at the larger diameter sizes, but $86 \%$ are found within $10 \%$ of the SAM-TOMAS $D_{\mathrm{pm}}\left(76 \%\right.$ of predicted $D_{\mathrm{pm}}$ are within $5 \%$ of SAM-TOMAS $D_{\mathrm{pm}}$ ). The small mean normalized bias (MNB) of -0.06 indicates a slight negative bias in the parameterization. This bias is generally seen towards the higher final $D_{\mathrm{pm}}$ values in the simulations $(>250 \mathrm{~nm})$, which are reached only by the most aged plumes with the heaviest aerosol loads. The $\sigma$ plot (Fig. 6b) shows a similar correlation coefficient $\left(R^{2}=0.91\right)$ and has a slope of 0.93 . The MNB is 0.01 and $77 \%$ of the predicted $\sigma$ points are within $5 \%$ of the $\sigma$ calculated from SAM-TOMAS. The cluster of points near $\sigma=1.2-1.3$ is indicative of the modal-width steady-state limit. This limit is not captured by the $\sigma$ parameterization, which assumes a smooth function towards even lower $\sigma$ values.

\subsection{Sensitivity of aged size distribution to input parameters}

Figures 7 and 8 show the sensitivities of the parameterization outputs ( $D_{\mathrm{pm}}$ and $\sigma$, respectively) to the input parameters $\left(D_{\mathrm{pm} 0}, \sigma_{0}\right.$, mass flux, fire area, wind speed, time, and mixing depth) as determined by the GEM-SA emulation of the SAM-TOMAS output. (Note that distance was used as the dependent variable in Fig. 4, while we use time in the emulator. Time can be converted to distance by multiplying by the wind speed.) In every panel, each line shows the change in $D_{\text {pm }}$ (Fig. 7) or $\sigma$ (Fig. 8) as an input parameter (e.g., $D_{\mathrm{pm} 0}$ in panel a) is varied systematically from its minimum to maximum tested value with a randomly chosen set of the other six input parameters. Each panel contains 100 lines, 

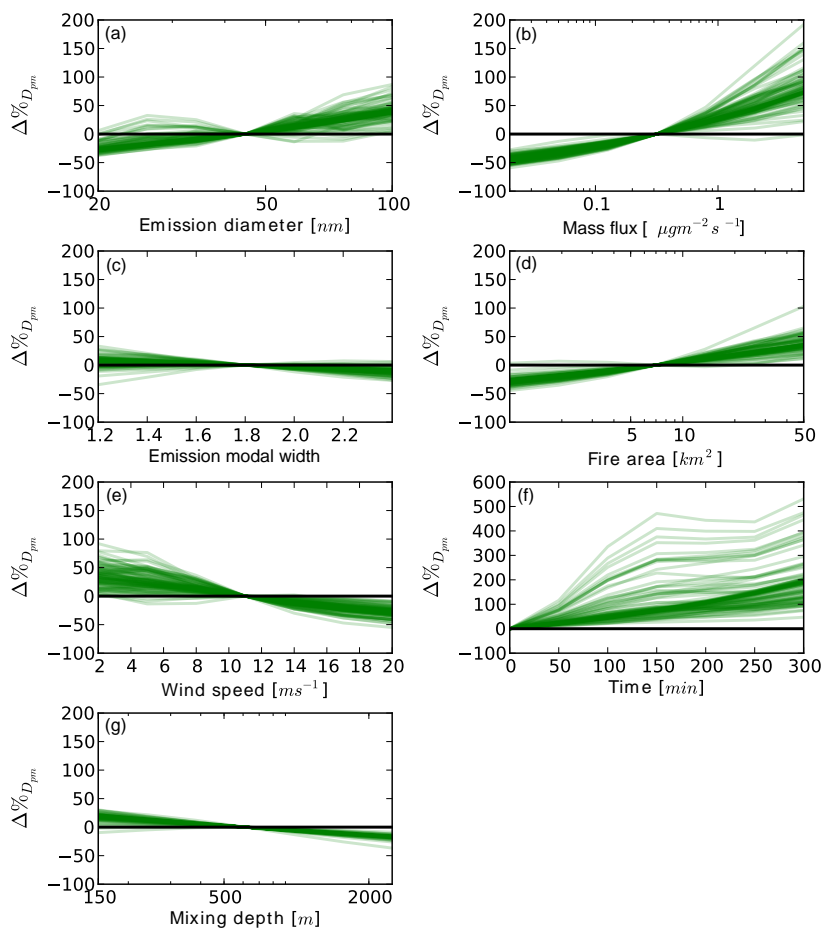

Figure 7. Sensitivity plots for the seven input parameters to the GEM-SA $D_{\text {pm }}$ parameterization. For each panel, a single input parameter is varied systematically from its minimum to maximum value for 100 randomly chosen sets of the other six parameters (100 lines in each panel). The sensitivities are shown as percent change in final $D_{\mathrm{pm}}$, individually normalized to the value at the center of the $x$ axis (to zero in time).

which means that 100 sets of the six other input parameters were randomly chosen to make these lines. We normalize each line by the value of $D_{\mathrm{pm}}$ or $\sigma$ at the midpoint of the $x$ axis (i.e., where the input parameter is at the midpoint of its tested range). For time since emission (panel f) we normalize by the values at $t=0 \mathrm{~min}$ instead of at the midpoint of the range. These plots therefore show the percent change in $D_{\mathrm{pm}}$ or $\sigma, \Delta \%_{\text {output }}$, as each input is changed from its midpoint value (or $t=0 \mathrm{~min}$ for time) in order to emphasize the parameterization's output response to each isolated input variable.

The $D_{\mathrm{pm}}$ sensitivity plots (Fig. 7) show a number of welldefined responses of $D_{\mathrm{pm}}$ to the inputs. $D_{\mathrm{pm}}$ increases monotonically with increases in mass flux and fire area (Fig. 5b, d) and decreases nearly monotonically with wind speed. These trends are due to the interrelationships of these inputs with starting number concentration. These results are consistent with Figs. 4 and 5, where $D_{\mathrm{pm}}$ increased with increasing $\mathrm{d} M / \mathrm{d} x$ in the SAM-TOMAS simulations. Additionally, the $D_{\mathrm{pm}}$ also decreases monotonically with mixing depth (albeit more weakly than mass flux, fire area, and wind speed), so $\mathrm{d} M / \mathrm{d} x \mathrm{~d} z$ may also be a good proxy for biomass-burning size-distribution aging (evaluated in
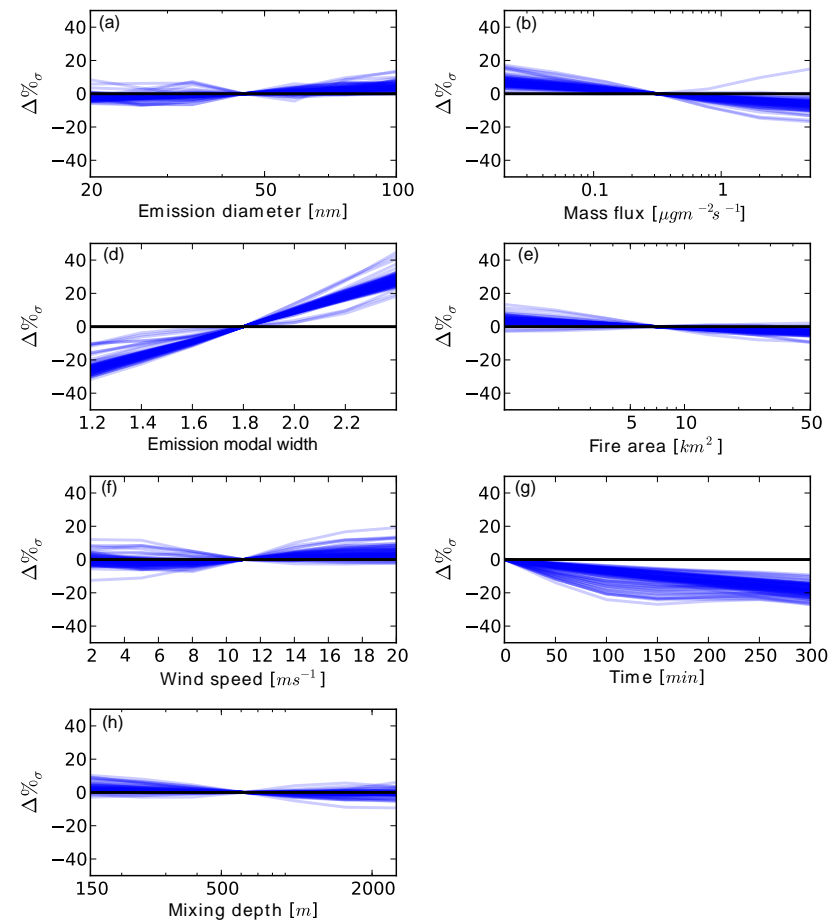

Figure 8. Sensitivity plots for the seven input parameters to the GEM-SA $\sigma$ emulator parameterization. For each panel, a single input parameter is varied systematically from its minimum to maximum value for 100 randomly chosen sets of the other six parameters (100 lines in each panel). The sensitivities are shown as percent change in final $\sigma$, individually normalized to the center value of the $x$ axis (to zero in time).

Sect. 3.4). Higher $\mathrm{d} M / \mathrm{d} x$ and $\mathrm{d} M / \mathrm{d} x \mathrm{~d} z$ values lead to higher initial number concentration in these plumes, which drive higher rates of coagulation due the squared dependence of coagulation rate on number concentrations.

$D_{\text {pm }}$ also increases nearly monotonically with time (the regions of slight decreases with time show that the parameterization is not necessarily always physically representative due to the statistical nature of the fit over the parameter space). The rapid rise in $D_{\mathrm{pm}}$ for time $<2 \mathrm{~h}$ is due to the high $N$ and coagulation rates near the source. As dilution and coagulation progress, $N$ decreases and coagulation slows, resulting in a slowing of $D_{\mathrm{pm}}$ increase. Mass flux has the largest range of output $D_{\text {pm }}$ associated with the input ranges specified here $(\sim-50$ to $+100 \%)$.

The relationship between $D_{\mathrm{pm}}$ and the initial size parameters $\left(D_{\mathrm{pm} 0}\right.$ and $\left.\sigma_{0}\right)$ is more complicated. Neither $D_{\mathrm{pm} 0}$ nor $\sigma_{0}$ show monotonic increases or decreases in $D_{\mathrm{pm}}$ due to changes in either of these isolated inputs. In general, there is an increasing trend in output $D_{\text {pm }}$ with increasing $D_{\text {pm0 }}$, but for some cases it decreases. These decreases in $D_{\mathrm{pm}}$ are likely due to (1) decreasing particle number concentrations with increasing $D_{\mathrm{pm} 0}$, which leads to reduced coagulation rates and, (2) imperfections in the statistical fit of the pa- 
rameter space. The larger $\sigma_{0}$ indicates broader emission size distributions, with more large particles and small particles. Since coagulation progresses fastest between large and small particles (as opposed to particles of approximately the same size), this favors higher $D_{\mathrm{pm}}$ at higher $\sigma$. However, the initial particle number decreases with increasing $\sigma$, which lowers the coagulation rate and leads to lower $D_{\mathrm{pm}}$.

The emulator-derived $\sigma$ sensitivities are shown in Fig. 8. Since we expect $\sigma$ to converge towards an asymptotic limit with coagulational processing (Fig. 4b, d), we see with those input parameters associated with higher plume number density (mass flux, fire area, wind speed ${ }^{-1}$, mixing depth ${ }^{-1}$ ), which gave monotonic increases for $D_{\mathrm{pm}}$, show mixed results for $\sigma$ due to variability in the initial $\sigma_{0}$. The time sensitivity plot (Fig. 8f) shows decreasing $\sigma$ with time similar to Fig. $4 b$ and d.

Emission $\sigma_{0}$ shows the most pronounced and largest magnitude effect on output $\sigma(\sim-30$ to $+30 \%)$. Thus, the timescales for $\sigma$ evolving towards 1.2 are longer than the timescales tested here for even the densest plumes. These sensitivity plots show that there is less variability in $\sigma$ than in $D_{\mathrm{pm}}$ over the tested input space.

\subsection{Simplified fits to the aged size distributions}

In addition to the GEM-SA emulator fits, we determined simplified fits for both $D_{\mathrm{pm}}$ and $\sigma$ based on the behavior in Figs. 4 and 5. These fits are easier to implement in regional and global aerosol models than the full GEM-derived parameterization. These equations are meant to produce approximate estimates of $D_{\mathrm{pm}}$ and $\sigma$ throughout plume sizedistribution aging. The equations require: the initial value of the size parameter of interest $\left(D_{\mathrm{pm} 0}\right.$ or $\left.\sigma_{0}\right)$, a value proportional to the plume aerosol loading $(\mathrm{d} M / \mathrm{d} x \mathrm{~d} z$ : mass flux - fire area/wind speed/mixing depth or $\mathrm{d} M / \mathrm{d} x$ : mass flux - fire area/wind speed), and time since emission from the source fire (time). (Distance may also be used in these equations rather than time, and distance/wind speed should be used in place of time.) The functional forms fitted for $D_{\mathrm{pm}}$ and $\sigma$ are found below.

$$
\begin{aligned}
& D_{\mathrm{pm}}=D_{\mathrm{pm} 0}+A[\mathrm{~d} M / \mathrm{d} x]^{b}(\text { time })^{c}, \\
& D_{\mathrm{pm}}=D_{\mathrm{pm} 0}+A[\mathrm{~d} M / \mathrm{d} x \mathrm{~d} z]^{b}(\text { time })^{c}, \\
& \sigma=\sigma_{0}+A[\mathrm{~d} M / \mathrm{d} x]^{b}(\text { time })^{c}\left(1.2-\sigma_{0}\right), \\
& \sigma=\sigma_{0}+A[\mathrm{~d} M / \mathrm{d} x \mathrm{~d} z]^{b}(\text { time })^{c}\left(1.2-\sigma_{0}\right),
\end{aligned}
$$

where $A, b$, and $c$ are determined by fitting each equation to the SAM-TOMAS data. For these empirical equations, the unit of $\mathrm{d} M / \mathrm{d} x$ is $\mathrm{kg} \mathrm{m}^{-1}, \mathrm{~d} M / \mathrm{d} x \mathrm{~d} z$ is $\mathrm{kg} \mathrm{m}^{-2}, D_{\mathrm{pm}}$ is nanometer, and time since emission is minute. It should be noted that the equations for $D_{\mathrm{pm}}$ and $\sigma$ are designed to be independent of each other (i.e., $D_{\mathrm{pm}}$ is not dependent on $\sigma_{0}$ ), which differs from the GEM-SA emulator. The aerosol loading parameter $\mathrm{d} M / \mathrm{d} x$ was chosen based on the stratification seen in Figs. $4 \mathrm{c}$ and $5 . \mathrm{d} M / \mathrm{d} x \mathrm{~d} z$ was tested as well, as it incorporates the variance associated with mixing depth into the fit. The fit to $\mathrm{d} M / \mathrm{d} x$ rather than $\mathrm{d} M / \mathrm{d} x \mathrm{~d} z$ may be advantageous because we expect mixing depth of the plume to be one of the more uncertain parameters in an atmospheric model, and the $D_{\mathrm{pm}}$ sensitivities to mixing depth tend to be smaller than those to mass flux, fire area, and wind speed in the GEM-SA emulator (Fig. 7). The $\sigma$ fits introduce a fourth factor, $\left(1.2-\sigma_{0}\right)$, which represents the difference between the SAM-TOMAS infinite-coagulation limit (Fig. 4b and d) and the initial modal width.

The scalar $A, b$, and $c$ variables were fit to the ensemble of SAM-TOMAS data. Their values are summarized in Table 3. The fits were tested against independent SAMTOMAS data in Figs. $9\left(D_{\mathrm{pm}}\right)$ and $10(\sigma)$. The simplified $D_{\mathrm{pm}}$ parameterizations, as expected, are not as good a fit of the SAM-TOMAS data as the GEM-SA emulator (Fig. 6). The fit statistics for the simple parameterizations are as follows: $D_{\mathrm{pm}}(\mathrm{d} M / \mathrm{d} x)$ has slope $=0.82, R^{2}=0.67$, and $\mathrm{MNB}=0.003 ; D_{\mathrm{pm}}(\mathrm{d} M / \mathrm{d} x \mathrm{~d} z)$ has slope $=0.98, R^{2}=0.77$, and $\mathrm{MNB}=0.008$. The fit using $\mathrm{d} M / \mathrm{d} x \mathrm{~d} z$ generally performs better than that with $\mathrm{d} M / \mathrm{d} x$. The simple $\sigma$ fit also did not perform as well as the GEM-SA emulator with fit statistics of slope $=0.64, R^{2}=0.78$, and $\mathrm{MNB}=0.02$ for $\sigma(\mathrm{d} M / \mathrm{d} x)$ and slope $=0.65, R^{2}=0.79$, and $\mathrm{MNB}=0.01$ for $\sigma(\mathrm{d} M / \mathrm{d} x \mathrm{~d} z)$. Thus, $\mathrm{d} M / \mathrm{d} x \mathrm{~d} z$ fits do yield better results than $\mathrm{d} M / \mathrm{d} x$ (in particular for $D_{\mathrm{pm}}$ ); however, a user may choose to use the $\mathrm{d} M / \mathrm{d} x$ fit when the mixing depth is unknown. We note that these fits are only valid within the parameter ranges shown in Table $1 . \mathrm{d} M / \mathrm{d} V$ was also tested as a parameter within these simplified parameterization but did not yield better agreements for either $D_{\mathrm{pm}}$ or $\sigma$ than $\mathrm{d} M / \mathrm{d} x \mathrm{~d} z$ despite incorporating an additional plume parameter (initial plume $y$ extent). This is because $\mathrm{d} M / \mathrm{d} x \mathrm{~d} z$ is the product of $\mathrm{d} M / \mathrm{d} V$ and the initial plume width; since wider plumes are less susceptible to dilution than narrower plumes, $\mathrm{d} M / \mathrm{d} x \mathrm{~d} z$ captures this plume-width effect while $\mathrm{d} M / \mathrm{d} V$ does not.

\subsection{OA production/loss}

One of the limitations of the coagulation-only parameterizations derived in this paper is that they do not include the effects of potential condensation/evaporation of organic aerosol on the aged biomass-burning size distribution. Both condensational growth and evaporative loss of OA have been observed previously in chamber studies and the field due to OA production or evaporation from dilution/chemistry $(\mathrm{Cu}-$ bison et al., 2011; Hecobian et al., 2011; Hennigan et al., 2011; Grieshop et al., 2009; Ortega et al., 2013; Jolleys et al., 2015; Vakkari et al., 2014). Konovalov et al. (2015) has emphasized the importance of OA simulation in modeling longrange $(>1000 \mathrm{~km}$ ) plume evolution. Thus, in order to predict biomass-burning aerosol mass, and thus the aerosol size distribution, we must understand how OA evolves in biomassburning plumes. 

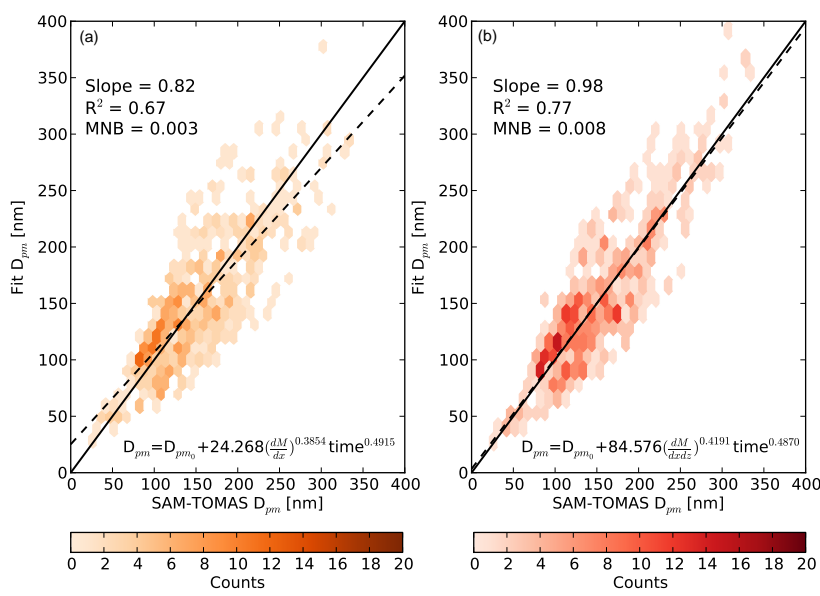

Figure 9. One-to-one plot showing simplified $D_{\text {pm }}$ fits vs. SAMTOMAS for (a) $\mathrm{d} M / \mathrm{d} x$ and (b) $\mathrm{d} M / \mathrm{d} x \mathrm{~d} z$. The black line is the oneto-one line. The dashed black line is the line of best fit. $N=624$.

Table 3. Best-fit parameters for the simplified $D_{\mathrm{pm}}$ and $\sigma \mathrm{SAM}-$ TOMAS parameterizations (Eqs. 1-4).

\begin{tabular}{lrrrr}
\hline Fit & Eq. & \multicolumn{3}{c}{ Parameter } \\
\cline { 3 - 5 } & & $A$ & $b$ & $c$ \\
\hline$D_{\mathrm{pm}}(\mathrm{d} M / \mathrm{d} x)$ & $(1)$ & 4.268 & 0.3854 & 0.4915 \\
$D_{\mathrm{pm}}(\mathrm{d} M / \mathrm{d} x \mathrm{~d} z)$ & $(2)$ & 84.58 & 0.4191 & 0.4870 \\
$\sigma(\mathrm{d} M / \mathrm{d} x)$ & $(3)$ & 0.05940 & 0.1915 & 0.3569 \\
$\sigma(\mathrm{d} M / \mathrm{d} x \mathrm{~d} z)$ & $(4)$ & 0.2390 & 0.1889 & 0.3540 \\
\hline
\end{tabular}

Here we present a simple correction to our coagulationonly parameterizations to account for in-plume OA production/loss, assuming that this production/loss is known. This correction assumes all SOA condenses onto existing particles (no new-particle formation). Each parameterization presented in this paper may be corrected to include OA production/evaporation using the corrections below. We assume that the OA production or loss does not affect the coagulation rates or $\sigma$ but rather acts to increase the final $D_{\mathrm{pm}}$. These assumptions are imperfect as irreversible condensation (evaporation) decreases (increases) $\sigma$; however, $\sigma$ is preserved during condensation or evaporation of semi-volatile material (Pierce et al., 2011). Regardless, for the relatively small amounts of OA condensation/evaporation considered here, the change in $\sigma$ and coagulation rates should be minor. For a factor of $25 \%$ growth in diameter from SOA, which may be expected for a factor of 2 increase in OA mass with a small change in sigma, we expect coagulation rates to stay within about $10 \%$ (Seinfeld and Pandis, 2006). For larger changes in OA mass (more than a factor of $\sim 2$ ) due to production/loss, our simple correction will have uncertainties due to these assumptions. Our correction to the final $D_{\text {pm }}$ has the following form:
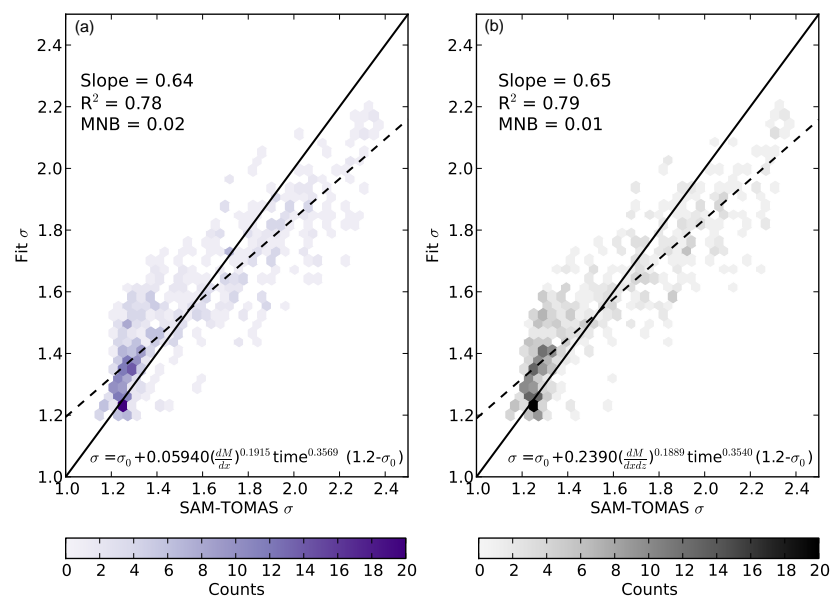

Figure 10. One-to-one plot showing simplified $\sigma$ fits vs. SAMTOMAS for (a) $\mathrm{d} M / \mathrm{d} x$ and (b) $\mathrm{d} M / \mathrm{d} x \mathrm{~d} z$. The solid black line is the one-to-one line. The dashed black line is the line of best linear fit. $N=624$.

$$
\begin{aligned}
& D_{\mathrm{pm} \text { w/OA prod/loss }}=D_{\mathrm{pm} \text { w/o OA prod/loss }}
\end{aligned}
$$

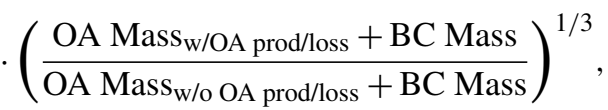

where $D_{\text {pm w/o OA prod/loss }}$ is the final $D_{\text {pm }}$ from the coagulation-only GEM-SA emulator parameterization, the biomass-burning aerosol OA mass (with and without additional production or loss) is in kilograms (per particle or volume of air) and the $\mathrm{BC}$ mass is in kilograms (per particle or volume of air). Thus, for a doubling of OA due to SOA production (one of the larger enhancements found in Hennigan et al., 2011), particles that contain negligible BC will grow in diameter by $26 \%$ above the coagulation-only predictions. If the particles contained $50 \% \mathrm{BC}$, then the diameter growth would only be $14 \%$.

While these changes are expected to be on the large end for growth by SOA production, they are significantly smaller than the $\sim 200 \%$ variability in aged $D_{\mathrm{pm}}$ due to coagulation over the range of initial fire conditions (Fig. 7). For example, variations in wind speed, mass flux, and fire area alone can independently cause variability in the aged $D_{\mathrm{pm}}$ by a factor of 2 due to changes in coagulation rates while variability in condensational growth appears to cause much smaller uncertainties $(\sim 25 \%)$ in the aged $D_{\mathrm{pm}}$. This indicates that although SOA condensational growth is certainly important in shaping particle composition and total particle mass, it is not among the most dominant factors determining the aged $D_{\text {pm }}$ compared to those fire-condition parameters controlling coagulational growth. It should be noted, however, that the $D_{\text {pm }}$ growth attributed to OA condensation is not accompanied by a change in particle number (additional OA mass is distributed among existing particles), whereas a similar in- 
crease in $D_{\text {pm }}$ growth by coagulation would only have an accompanying decrease in particle number. Thus, the changes to the aerosol size distribution and climatic influence of a size change due to coagulation and condensation are different.

\subsection{Estimating aged size distributions observed at the Mt. Bachelor Observatory}

The simplified fits presented in Sect. 3.4 (Eqs. 1-4) were tested against size-distribution measurements of biomassburning plumes observed at the Mt. Bachelor Observatory (MBO) in central Oregon $\left(43.98^{\circ} \mathrm{N}, 121.69^{\circ} \mathrm{W}\right.$; $2764 \mathrm{~m}$ a.s.l.). $\mathrm{MBO}$ is a mountaintop site that has been in operation since 2004 (Jaffe et al., 2005). An intensive campaign was performed during the summer of 2015 to measure aerosol physical and optical properties of wildfire emissions (Laing et al., 2016). During this campaign aerosol size distributions from 14.1 to $637.8 \mathrm{~nm}$ were measured with a scanning mobility particle sizer (SMPS). Additional details about MBO and the sampling campaign can be found in Laing et al. (2016).

We identified 11 biomass-burning plumes in August (Table 4). Criteria for plume selection was aerosol scattering $>20 \mathrm{Mm}^{-1}$ and $\mathrm{CO}>150 \mathrm{ppbv}$ for at least an hour, a strong correlation $\left(R^{2}>0.80\right)$ between aerosol scattering and $\mathrm{CO}$, and consistent backward trajectories indicating transport over known fire locations. We calculated back trajectories to determine fire locations using the National Oceanic and Atmospheric Administration Hybrid Single-Particle Lagrangian Integrated Trajectory (HYSPLIT) model, version 4 (Draxler, 1999; Draxler and Hess, 1997, 1998; Stein et al., 2015), with Global Data Assimilation System $\left(\mathrm{GDAS}, 1^{\circ} \times 1^{\circ}\right)$ data. The Mt. Bachelor summit is located at $\sim 1500 \mathrm{~m}$ a.m.g.l. (above model ground level), so the back-trajectory starting heights of 1300,1500 , and $1700 \mathrm{~m}$ a.m.g.l. were chosen (Ambrose et al., 2011). Fire locations were identified using Moderate Resolution Imaging Spectroradiometer (MODIS) satellite-derived active fire counts (http://activefiremaps.fs.fed.us/; Justice et al., 2002).

For the plume aerosol loading parameterization inputs in Eqs. (1)-(4), we used Fire INventory from NCAR (FINN) daily-averaged fire area and fire-emission estimates (Wiedinmyer et al., 2011). Multiple FINN data points in the same vicinity were combined based on the location of large-wildfire incidents tracked by the National Interagency Fire Center (NIFC) (http://activefiremaps.fs.fed.us/). We calculated the mass flux for the aerosol-loading estimates $(\mathrm{d} M / \mathrm{d} x \mathrm{~d} z$ and $\mathrm{d} M / \mathrm{d} x)$ using these FINN OC $+\mathrm{BC}$ emissions $\left(\mathrm{kg} \mathrm{day}^{-1}\right)$ and FINN fire area data $\left(\mathrm{km}^{2}\right)$. Mixing depth was defined as the mixing depth at the source location of the fire in the GDAS $\left(1^{\circ} \times 1^{\circ}\right)$ data. Wind speed was also extracted from GDAS data and was calculated as the average wind speed from the ground to the defined mixing height. When no data were available, the mixing height and wind speed were set to $660 \mathrm{~m}$ and $8.5 \mathrm{~m} \mathrm{~s}^{-1}$ based on the median

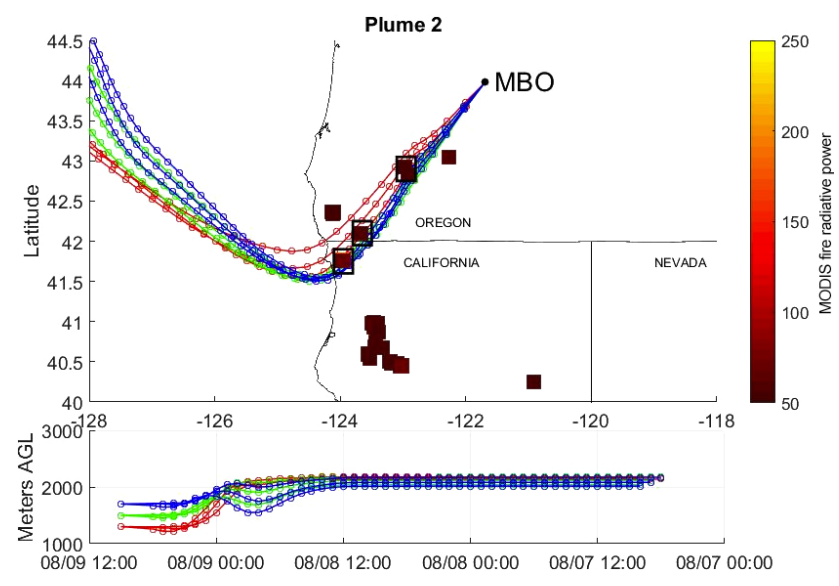

Figure 11. Back trajectories from plume 2 observed at MBO. The colored squares represent fires during the time of the back trajectory and are colored by fire radiative power. The black squares indicate the fire areas used in the parameterization to estimate $D_{\mathrm{pm}}$ and $\sigma$.

value of the rest of the plumes. We assumed the emission diameter $\left(D_{\mathrm{pm} 0}\right)$ to be $100 \mathrm{~nm}$, and we calculated $\sigma$ using initial $\sigma_{0}$ of 1.6, 1.9, and 2.4, to be discussed later. We estimated the transport time from plume back trajectories, and these values ranged from 4.5 to $35 \mathrm{~h}$.

The measured and calculated size-distribution diameter and modal widths for each plume at MBO are summarized in Table 4. We calculated $D_{\mathrm{pm}}$ and $\sigma$ as the geometric mean diameter and geometric standard deviation of the plumeaveraged size distribution as measured by the SMPS, respectively. The plume-averaged size distributions may be influenced by non-biomass-burning particles included along the trajectory from the wildfire. Plumes 1, 2, and 4 have bimodal distributions. The second mode (Aitken mode) of these distributions are an example of influence from a non-biomassburning source. These three bimodal distributions have inflated $\sigma$ values, which will be addressed later. Due to the large number of fires in Northern California and Oregon during the summer of 2015, some of the plumes observed at MBO were influenced by more than one fire (e.g., Fig. 11). For these plumes, we calculated aged $D_{\mathrm{pm}}$ and $\sigma$ values for each fire area (black squares in Fig. 11) and a weighted average based on aerosol loading $(\mathrm{d} M / \mathrm{d} x$ or $\mathrm{d} M / \mathrm{d} x \mathrm{~d} z)$ was taken. Column 3 in Table 4 indicates how many fire areas were averaged for each plume.

Figure 12 shows the predicted aged $D_{\mathrm{pm}}$ plotted against the observed values for both the $\mathrm{d} M / \mathrm{d} x$ and $\mathrm{d} M / \mathrm{d} x \mathrm{~d} z$ forms of the simple parameterization. An initial $D_{\mathrm{pm} 0}$ of $100 \mathrm{~nm}$ was assumed. Equation (2) (using aerosol mass loading $\mathrm{d} M / \mathrm{d} x \mathrm{~d} z)$ estimates $D_{\mathrm{pm}}$ somewhat more accurately ( $y=$ $\left.0.93 x+17.1, R^{2}=0.551\right)$ than Eq. (1), which uses aerosol mass loading $\mathrm{d} M / \mathrm{d} x\left(y=0.62 x+53.1, R^{2}=0.532\right)$. Over half of the variability in the observed $D_{\mathrm{pm}}$ was captured by the simplified fits. Thus, the simple parameterizations show 
Table 4. Measured and calculated $D_{\mathrm{pm}}$ and $\sigma$ of biomass-burning plumes observed at MBO in August 2015. For the calculated $D_{\mathrm{pm}}$ and $\sigma$, the initial size parameters used were $D_{\mathrm{pm} 0}=100 \mathrm{~nm}$ and $\sigma_{0}=1.9$.

\begin{tabular}{|c|c|c|c|c|c|c|c|c|}
\hline \multirow[b]{3}{*}{ Plume } & \multirow[b]{3}{*}{ Plume date and time (UTC) } & \multirow[b]{3}{*}{ No. of fire areas } & & & \multicolumn{4}{|c|}{ Calculated } \\
\hline & & & \multicolumn{2}{|c|}{ Measured (SMPS) } & \multicolumn{2}{|c|}{ using $\mathrm{d} M / \mathrm{d} x$} & \multicolumn{2}{|c|}{ using $\mathrm{d} M / \mathrm{d} x \mathrm{~d} z$} \\
\hline & & & $D_{\mathrm{pm}}(\mathrm{nm})$ & $\sigma$ & $D_{\mathrm{pm}}(\mathrm{nm})$ & $\sigma$ & $D_{\mathrm{pm}}(\mathrm{nm})$ & $\sigma$ \\
\hline 1 & 9 Aug 2015 03:00-04:00 & 3 & 136.1 & 1.95 & 140.7 & 1.64 & 151.1 & 1.59 \\
\hline 2 & 9 Aug 2015 05:00-07:00 & 3 & 144.0 & 1.77 & 140.8 & 1.64 & 152.0 & 1.58 \\
\hline 3 & 10 Aug 2015 03:00-05:00 & 3 & 190.1 & 1.50 & 140.9 & 1.63 & 149.7 & 1.58 \\
\hline 4 & 23 Aug 2015 03:55-07:00 & 1 & 162.5 & 1.89 & 145.5 & 1.63 & 162.4 & 1.57 \\
\hline 5 & 24 Aug 2015 04:00-07:25 & 1 & 201.1 & 1.59 & 167.5 & 1.55 & 184.7 & 1.49 \\
\hline 6 & 24 Aug 2015 07:30-11:20 & 1 & 217.5 & 1.52 & 190.1 & 1.50 & 230.1 & 1.40 \\
\hline 7 & 24 Aug 2015 13:00-18:00 & 1 & 212.5 & 1.49 & 193.9 & 1.48 & 237.8 & 1.37 \\
\hline 8 & 24 Aug 2015 03:50-06:50 & 1 & 192.2 & 1.54 & 161.4 & 1.57 & 172.6 & 1.52 \\
\hline 9 & 27 Aug 2015 09:00-13:00 & 3 & 192.9 & 1.50 & 194.2 & 1.49 & 220.6 & 1.43 \\
\hline 10 & 28 Aug 2015 08:00-11:15 & 3 & 183.4 & 1.54 & 182.1 & 1.50 & 203.2 & 1.43 \\
\hline 11 & 28 Aug 2015 17:40-19:40 & 3 & 176.7 & 1.60 & 181.4 & 1.50 & 202.0 & 1.43 \\
\hline
\end{tabular}

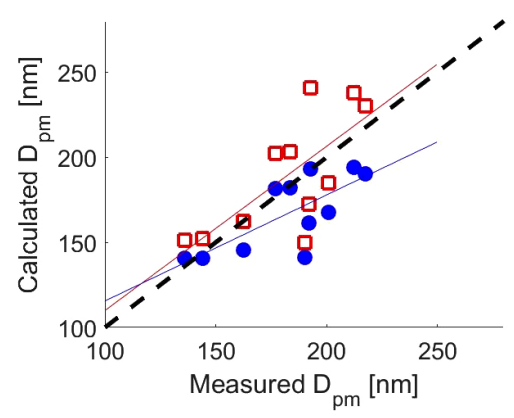

Figure 12. Scatterplot showing calculated and measured $D_{\mathrm{pm}}$ for biomass-burning plumes observed at MBO in August 2015. The blue circles represent $D_{\mathrm{pm}}$ calculated using Eq. (1) $(\mathrm{d} M / \mathrm{d} x)$, and the red circles represent $D_{\mathrm{pm}}$ calculated using Eq. (2) $(\mathrm{d} M / \mathrm{d} x \mathrm{~d} z)$.

skill at predicting the aged $D_{\text {pm }}$ values relative to choosing a constant value of aged $D_{\mathrm{pm}}$ as is typically done in regional and global models.

Figure 13 shows the predicted aged $\sigma$ plotted against the observed values for both parameterization forms. Both parameterizations do not predict modal width as well as $D_{\mathrm{pm}}$ (Fig. 12). The calculated modal width changed significantly when using different emission $\sigma_{0}$. Janhäll et al. (2010) found the $\sigma$ of fresh biomass-burning emissions to range from $\sim 1.6$ to 1.9 . When using a $\sigma_{0}$ of 1.6 , we underestimated all of the $\sigma$ values. Using a $\sigma_{0}$ of 1.9 , we improved the estimation of aged $\sigma$ ranging from 1.4 to 1.6 (Fig. 13a). The three higher measured $\sigma$ values are from the bimodal plumes mentioned previously, which have larger $\sigma$ values than would be due strictly to the biomass-burning plume. We found that using a $\sigma_{0}$ of 2.4 provided the best fit for all of the measured plumes (Fig. 13b), 2.4 being the $\max \sigma_{0}$ value from Table 2. The $\sigma$ simplified fits using $\sigma_{0}=2.4$ have statistics of $y=0.50+1.00$ and $R^{2}=0.513$ for $\sigma(\mathrm{d} M / \mathrm{d} x)$ and

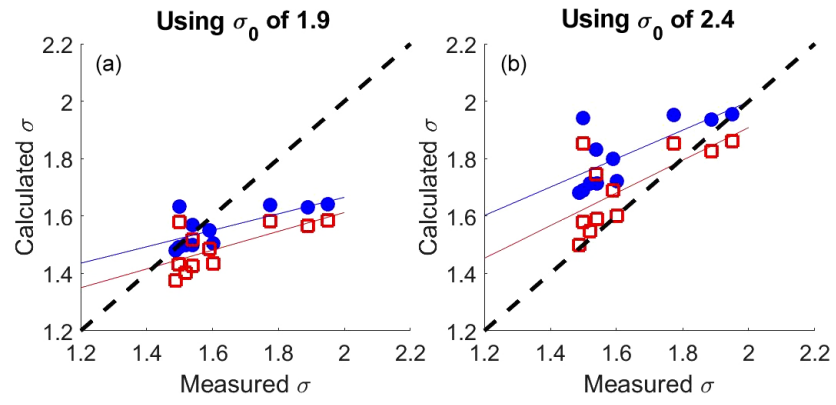

Figure 13. Scatterplots showing calculated and measured modal width $(\sigma)$ for biomass-burning plumes observed at MBO in August 2015. The blue circles represent $\sigma$ calculated using Eq. (3) $(\mathrm{d} M / \mathrm{d} x)$, and the red circles represent $\sigma$ calculated using Eq. (4). $(\mathrm{d} M / \mathrm{d} x \mathrm{~d} z)$. Different emission modal-width values $\left(\sigma_{0}\right)$ were used to calculate $\sigma$ : (a) used a $\sigma_{0}$ of 1.9 and (b) used a $\sigma_{0}$ of 2.4.

$y=0.57+0.77$ and $R^{2}=0.468$ for $\sigma(\mathrm{d} M / \mathrm{d} x \mathrm{~d} z)$. Thus, both parameterizations do not predict modal width as well as $D_{\mathrm{pm}}$; however, these parameterizations do show skill relative to assuming a constant value of $\sigma$.

The results from the regional fires demonstrate that the parameterizations in Eqs. (1)-(4) can be successfully used to estimate aged biomass-burning size distributions in regional biomass-burning plumes with transport times up to 35 hours with significantly better skill than assuming fixed values for size-distribution parameters. More investigations of individual aged biomass-burning plumes, specifically with one clear source, should be completed to fully characterize this parameterization. 


\section{Conclusions}

We used the SAM-TOMAS LES model and an emulation technique to explore the evolution of biomass-burning aerosol size distributions due to coagulation and build coagulation-only parameterizations of this size-distribution evolution. We have also provided a simple correction to the parameterization for cases with net OA production or loss. We used the SAM-TOMAS model to simulate plume dispersion and aerosol coagulation. The SAM-TOMAS results show that the aged $D_{\text {pm }}$ can be largely described by $\mathrm{d} M / \mathrm{d} x$ and the distance from the source (or time since emission). These results also show that the aged $\sigma$ moves from $\sigma_{0}$ towards a value of 1.2 at a rate that depends on $\mathrm{d} M / \mathrm{d} x$.

The GEM-SA program was used to derive a $D_{\mathrm{pm}}$ and $\sigma$ emulator parameterization based on the SAM-TOMAS results. The parameterization requires seven input parameters: emission $D_{\mathrm{pm} 0}$, emission $\sigma_{0}$, mass flux, boundary-layer wind speed, fire area, plume mixing depth, and time since emission. The predicted $D_{\mathrm{pm}}$ and $\sigma$ can then be used as effective unimodal biomass-burning size-distribution parameters in regional and global aerosol models.

The $D_{\mathrm{pm}}$ parameterization showed the strongest sensitivities to those input parameters associated with the extent of aerosol loading within the plume (mass flux, fire area, wind speed). Across the fire area and wind speed ranges tested here, final $D_{\text {pm }}$ varied by $\pm 50 \%$. Mass flux had the largest associated $D_{\mathrm{pm}}$ sensitivity across the tested values ( -50 to $+100 \%)$. These sensitivities were larger than those associated with mixing depth $(\sim-20$ to $20 \%)$ or the initial sizedistribution parameters $\left(D_{\mathrm{pm} 0}: \sim-25\right.$ to $25 \% ; \sigma_{0}: \sim 15$ to $-15 \%)$. The $\sigma$ parameterization showed a uniform decrease in $\sigma$ with time and strong sensitivities to the emission $\sigma_{0}$ ( -30 to $30 \%$ ). This strong sensitivity to $\sigma_{0}$ can be attributed to the inertia in $\sigma$ evolution in simulations with large modal widths and relatively small mass loading, where $\sigma$ will not converge quickly to the coagulational limit (1.2).

The GEM-SA-derived parameterization performed relatively well against the SAM-TOMAS model with a correlation of $R^{2}=0.83$, slope of $m=0.92$, and a low mean normalized bias of MNB $=-0.06$ for $D_{\mathrm{pm}}$. The $\sigma$ parameterization has fit statistics of $R^{2}=0.93$, slope $=0.91$, and $\mathrm{MNB}=0.01$. The $\sigma$ parameterization was unable to capture the coagulational limit of 1.2 seen in the SAM-TOMAS results and instead extrapolated to lower values. This 1.2 limit differs from the $1.32 \sigma$ limit proposed by Lee (1983) due to the bin spacing in SAM-TOMAS being coarser than lognormal modes with these small modal widths.

We also provided simplified polynomial fits for $D_{\mathrm{pm}}$ and $\sigma$ (Eqs. 1-4, Table 3) for calculating aged $D_{\text {pm }}$ and $\sigma$ as independent functions of the fresh emission parameter $\left(D_{\mathrm{pm} 0}\right.$ or $\left.\sigma_{0}\right)$, the mass loading of the aerosol $(\mathrm{d} M / \mathrm{d} x$ or $\mathrm{d} M / \mathrm{d} x \mathrm{~d} z)$, and the time since emission from the source fire. The $\sigma$ fits also require a convergence term to account for the coagulational limit (1.2 in the SAM-TOMAS model). Tested against independent SAM-TOMAS data, the $D_{\mathrm{pm}}$ simplified fits performed as $D_{\mathrm{pm}}(\mathrm{d} M / \mathrm{d} x)$ with slope $=0.82, R^{2}=0.67$, and $\mathrm{MNB}=0.003$ and $D_{\mathrm{pm}}(\mathrm{d} M / \mathrm{d} x \mathrm{~d} z)$ with slope $=0.98$, $R^{2}=0.77$, and $\mathrm{MNB}=0.008$. The $\sigma$ simplified fits have statistics of slope $=0.64, R^{2}=0.78$, and $\mathrm{MNB}=0.02$ for $\sigma(\mathrm{d} M / \mathrm{d} x)$ and slope $=0.65, R^{2}=0.79$, and $\mathrm{MNB}=0.01$ for $\sigma(\mathrm{d} M / \mathrm{d} x \mathrm{~d} z)$. The equations requiring $(\mathrm{d} M / \mathrm{d} x \mathrm{~d} z)$ performed better than their $(\mathrm{d} M / \mathrm{d} x)$ counterparts as they also account for the aerosol layer depth.

We provided a correction for OA production/loss and showed that significant production of SOA within the plume $(\sim 100 \%$ OA mass enhancement) would cause a relatively small shift in the size distribution $D_{\mathrm{pm}}$ (14-26\% increase) compared to other factors that control the coagulation rate (e.g., $\mathrm{d} M / \mathrm{d} x$ ). We note, however, that OA production increases $D_{\mathrm{pm}}$ without loss of particle number while coagulation increases $D_{\mathrm{pm}}$ with a decrease in number; thus the climatic impact of condensation and coagulation is different. The simplified OA-production/loss correction assumes no change in $\sigma$ with condensational growth. Further testing should be done with explicit OA production and loss to better quantify the effects of condensation of the size-distribution evolution.

We tested the simplified fits for $D_{\mathrm{pm}}$ and $\sigma$ (Eqs. 1-4, Table 3) against 11 aged biomass-burning plumes observed at the Mt. Bachelor Observatory in August 2015. $D_{\text {pm }}$ was reasonably calculated using both measures of aerosol loading, $\mathrm{d} M / \mathrm{d} x$ and $\mathrm{d} M / \mathrm{d} x \mathrm{~d} z\left(R^{2}\right.$ values above 0.7 without an outlier). The fit of calculated $\sigma$ and measured $\sigma$ depended heavily on the assumed initial modal width, with an assumed $\sigma_{0}$ of 2.4 working best in our case ( $R^{2}$ values around 0.75 without an outlier). Despite the changes in calculated $D_{\mathrm{pm}}$ and $\sigma$ due to the estimated emission size distribution, the parameterizations captured the differences from plume to plume in regional biomass-burning plumes, which is based on estimated aerosol loading and transport times.

Our analysis does not include any cloud processing of the plume particles; i.e., the production of aqueous SOA within activated plume particles is not accounted for in our simple OA mass correction. The production of SOA within droplets could result in additional SOA mass being only added to the larger, activated particles during activation/evaporation cycling. This extra SOA mass would favor increases in the diameters of the larger particles of the size distribution only, which could create a bimodal size distribution and increase the overall coagulational rates in the plume (more, larger particles coagulate more rapidly with the small-diameter particles).

Future work includes (1) more testing of the parameterizations against real world observations of size-distribution aging and (2) incorporating the parameterizations into regional and global aerosol models for further evaluation against regional/global measurements. 


\section{Data availability}

The SAM-TOMAS and GEM-SA emulator data are available from the Colorado State University Digital Repository from the following persistent link: http://hdl.handle.net/ 10217/173045 (Pierce and Sakomoto, 2016). All data from the Mt. Bachelor Observatory are permanently archived at the University of Washington ResearchWorks site: http://hdl. handle.net/1773/36293 (Jaffe, 2016).

\section{The Supplement related to this article is available online at doi:10.5194/acp-16-7709-2016-supplement.}

Author contributions. K. M. Sakamoto, R. G. Stevens, and J. R. Pierce designed the study. K. M. Sakamoto performed the SAM-TOMAS simulations and created and evaluated the parameterizations. J. R. Laing tested the parameterizations size distributions of aged biomass-burning plumes observed at the Mt. Bachelor Observatory, and D. A. Jaffe oversaw the Mt. Bachelor measurements. K. M. Sakamoto prepared the manuscript with assistance from all co-authors.

Acknowledgements. NCEP Reanalysis data were provided by the NOAA/OAR/ESRL PSD, Boulder, Colorado, USA, from their website at http://www.esrl.noaa.gov/psd/. K. M. Sakamoto was funded by a Natural Sciences and Engineering Research Council of Canada (NSERC) PGS-M Fellowship. The authors gratefully acknowledge the NOAA Air Resources Laboratory (ARL) for the provision of the HYSPLIT transport model used in this publication.

Edited by: V.-M. Kerminen

\section{References}

Adams, P. J. and Seinfeld, J. H.: Predicting global aerosol size distributions in general circulation models, J. Geophys. Res.-Atmos., 107, 4310-4370, 2002.

Akagi, S. K., Craven, J. S., Taylor, J. W., McMeeking, G. R., Yokelson, R. J., Burling, I. R., Urbanski, S. P., Wold, C. E., Seinfeld, J. H., Coe, H., Alvarado, M. J., and Weise, D. R.: Evolution of trace gases and particles emitted by a chaparral fire in California, Atmos. Chem. Phys., 12, 1397-1421, doi:10.5194/acp-12-13972012, 2012.

Alonso-Blanco, E., Calvo, A. I., Pont, V., Mallet, M., Fraile, R., and Castro, A.: Impact of Biomass Burning on Aerosol Size Distribution, Aerosol Optical Properties and Associated Radiative Forcing, Aerosol Air Qual. Res., 006, 708-724, doi:10.4209/aaqr.2013.05.0163, 2014.

Ambrose, J. L., Reidmiller, D. R., and Jaffe, D. A.: Causes of High $\mathrm{O}_{3}$ in the Lower Free Troposphere over the Pacific Northwest as Observed at the Mt. Bachelor Observatory, Atmos. Environ., 45, 5302-5315, 2011.
Andreae, M. O. and Merlet, P.: Emission of trace gases and aerosols from biomass burning, Global Biogeochem. Cy., 15, 955-966, doi:10.1029/2000GB001382, 2001.

Boucher, O., Randall, D., Artaxo, P., Bretherton, C., Feingold, G., Forster, P., Kerminen, V.-M., Kondo, Y., Liao, H., Lohmann, U., Rasch, P., Satheesh, S. K., Sherwood, S., Stevens, B., and Zhang, X. Y.: Climate Change 2013: The Physical Science Basis. Contribution of Working Group I to the Fifth Assessment Report of the Intergovernmental Panel on Climate Change, edited by: Stocker, T. F., Qin, D., Plattner, G.-K., Tignor, M., Allen, S. K., Boschung, J., Nauels, A., Xia, Y., Bex, V., and Midgley, P. M., Cambridge University Press, 2013.

Capes, G., Johnson, B., McFiggans, G., Williams, P. I., Haywood, J., and Coe, H.: Aging of biomass burning aerosols over West Africa: Aircraft measurements of chemical composition, microphysical properties, and emission ratios, J. Geophys. Res., 113, D00C15, doi:10.1029/2008JD009845, 2008.

Carrico, C. M., Petters, M. D., Kreidenweis, S. M., Sullivan, A. P., McMeeking, G. R., Levin, E. J. T., Engling, G., Malm, W. C., and Collett Jr., J. L.: Water uptake and chemical composition of fresh aerosols generated in open burning of biomass, Atmos. Chem. Phys., 10, 5165-5178, doi:10.5194/acp-10-5165-2010, 2010.

Cubison, M. J., Ortega, A. M., Hayes, P. L., Farmer, D. K., Day, D., Lechner, M. J., Brune, W. H., Apel, E., Diskin, G. S., Fisher, J. A., Fuelberg, H. E., Hecobian, A., Knapp, D. J., Mikoviny, T., Riemer, D., Sachse, G. W., Sessions, W., Weber, R. J., Weinheimer, A. J., Wisthaler, A., and Jimenez, J. L.: Effects of aging on organic aerosol from open biomass burning smoke in aircraft and laboratory studies, Atmos. Chem. Phys., 11, 12049-12064, doi:10.5194/acp-11-12049-2011, 2011.

DeCarlo, P. F., Ulbrich, I. M., Crounse, J., de Foy, B., Dunlea, E. J., Aiken, A. C., Knapp, D., Weinheimer, A. J., Campos, T., Wennberg, P. O., and Jimenez, J. L.: Investigation of the sources and processing of organic aerosol over the Central Mexican Plateau from aircraft measurements during MILAGRO, Atmos. Chem. Phys., 10, 5257-5280, doi:10.5194/acp-10-52572010, 2010.

Draxler, R. R.: HYSPLIT_4 User's Guide, NOAA Technical Memorandum ERL ARL-230, June, 35 pp., 1999.

Draxler, R. R. and Hess, G. D.: Description of the HYSPLIT_4 modeling system, NOAA Technical Memo ERL ARL-224, December, 24 pp., 1997.

Draxler, R. R. and Hess, G. D.: An overview of the HYSPLIT_4 modelling system for trajectories, dispersion, and deposition, Aust. Meteorol. Mag., 47, 295-308, 1998.

Engelhart, G. J., Hennigan, C. J., Miracolo, M. A., Robinson, A. L., and Pandis, S. N.: Cloud condensation nuclei activity of fresh primary and aged biomass burning aerosol, Atmos. Chem. Phys., 12, 7285-7293, doi:10.5194/acp-12-7285-2012, 2012.

Freitas, S. R., Longo, K. M., Chatfield, R., Latham, D., Silva Dias, M. A. F., Andreae, M. O., Prins, E., Santos, J. C., Gielow, R., and Carvalho Jr., J. A.: Including the sub-grid scale plume rise of vegetation fires in low resolution atmospheric transport models, Atmos. Chem. Phys., 7, 3385-3398, doi:10.5194/acp-7-3385-2007, 2007.

Grieshop, A. P., Logue, J. M., Donahue, N. M., and Robinson, A. L.: Laboratory investigation of photochemical oxidation of organic aerosol from wood fires 1: measurement and simulation of 
organic aerosol evolution, Atmos. Chem. Phys., 9, 1263-1277, doi:10.5194/acp-9-1263-2009, 2009.

Haywood, J. and Boucher, O.: Estimates of the direct and indirect radiative forcing due to tropospheric aerosols: a review, Rev. Geophys., 38, 513-543, doi:10.1029/1999RG000078, 2000.

Hecobian, A., Liu, Z., Hennigan, C. J., Huey, L. G., Jimenez, J. L., Cubison, M. J., Vay, S., Diskin, G. S., Sachse, G. W., Wisthaler, A., Mikoviny, T., Weinheimer, A. J., Liao, J., Knapp, D. J., Wennberg, P. O., Kürten, A., Crounse, J. D., Clair, J. St., Wang, Y., and Weber, R. J.: Comparison of chemical characteristics of 495 biomass burning plumes intercepted by the NASA DC-8 aircraft during the ARCTAS/CARB-2008 field campaign, Atmos. Chem. Phys., 11, 13325-13337, doi:10.5194/acp-1113325-2011, 2011.

Hennigan, C. J., Miracolo, M. A., Engelhart, G. J., May, A. A., Presto, A. A., Lee, T., Sullivan, A. P., McMeeking, G. R., Coe, H., Wold, C. E., Hao, W.-M., Gilman, J. B., Kuster, W. C., de Gouw, J., Schichtel, B. A., Collett Jr., J. L., Kreidenweis, S. M., and Robinson, A. L.: Chemical and physical transformations of organic aerosol from the photo-oxidation of open biomass burning emissions in an environmental chamber, Atmos. Chem. Phys., 11, 7669-7686, doi:10.5194/acp-11-7669-2011, 2011.

Hennigan, C. J., Westervelt, D. M., Riipinen, I., Engelhart, G. J., Lee, T., Collett, J. L., Pandis, S. N., Adams, P. J., and Robinson, A. L.: New particle formation and growth in biomass burning plumes: An important source of cloud condensation nuclei, Geophys. Res. Lett., 39, L09805, doi:10.1029/2012GL050930, 2012.

Heringa, M. F., DeCarlo, P. F., Chirico, R., Tritscher, T., Dommen, J., Weingartner, E., Richter, R., Wehrle, G., Prévôt, A. S. H., and Baltensperger, U.: Investigations of primary and secondary particulate matter of different wood combustion appliances with a high-resolution time-of-flight aerosol mass spectrometer, Atmos. Chem. Phys., 11, 5945-5957, doi:10.5194/acp-11-59452011, 2011.

Huffman, J. A., Docherty, K. S., Mohr, C., Cubison, M. J., U1brich, I. M., Ziemann, P. J., Onasch, T. B., and Jimenez, J. L.: Chemically-Resolved Volatility Measurements of Organic Aerosol from Different Sources, Environ. Sci. Technol., 43, 5351-5357, doi:10.1021/es803539d, 2009.

Jacobson, M. Z.: Strong radiative heating due to the mixing state of black carbon in atmospheric aerosols, Nature, 409, 695-697, 2001.

Jaffe, D.: SMPS particle size data from the Mt. Bachelor Observatory for summer 2015, available at: http://hdl.handle.net/1773/ 36293, last access: 21 June 2016.

Jaffe, D., Prestbo, E., Swartzendruber, P., Weisspenzias, P., Kato, S., Takami, a, Hatakeyama, S., and Kajii, Y.: Export of atmospheric mercury from Asia, Atmos. Environ., 39, 3029-3038, doi:10.1016/j.atmosenv.2005.01.030, 2005.

Janhäll, S., Andreae, M. O., and Pöschl, U.: Biomass burning aerosol emissions from vegetation fires: particle number and mass emission factors and size distributions, Atmos. Chem. Phys., 10, 1427-1439, doi:10.5194/acp-10-1427-2010, 2010.

Jolleys, M. D., Coe, H., McFiggans, G., Taylor, J. W., O'Shea, S. J., Le Breton, M., Bauguitte, S. J.-B., Moller, S., Di Carlo, P., Aruffo, E., Palmer, P. I., Lee, J. D., Percival, C. J., and Gallagher, M. W.: Properties and evolution of biomass burning organic aerosol from Canadian boreal forest fires, Atmos. Chem. Phys., 15, 3077-3095, doi:10.5194/acp-15-3077-2015, 2015.
Justice, C., Giglio, L., Korontzi, S., Owens, J., Morisette, J., Roy, D., Descloitres, J., Alleaume, S., Petitcolin, F., and Kaufman, Y.: The MODIS fire products, Remote Sens. Environ., 83, 244-262, doi:10.1016/S0034-4257(02)00076-7, 2002.

Kennedy, M. and O'Hagan, A.: Bayesian calibration of computer models, J. R. Stat. Soc. Ser. B, 63, 425-464, 2001.

Kennedy, M., Anderson, C., O’Hagan, A., Lomas, M., Woodward, I., Gosling, J. P., and Heinemeyer, A.: Quantifying uncertainty in the biospheric carbon flux for England and Wales, J. R. Stat. Soc. A, 171, 109-135, doi:10.1111/j.1467-985X.2007.00489.x, 2008.

Khairoutdinov, M. F. and Randall, D. A.: Cloud resolving modeling of the ARM summer 1997 IOP: Model formulation, results, uncertainties, and sensitivities, J. Atmos. Sci., 60, 607-625, 2003.

Konovalov, I. B., Beekmann, M., Berezin, E. V., Petetin, H., Mielonen, T., Kuznetsova, I. N., and Andreae, M. O.: The role of semi-volatile organic compounds in the mesoscale evolution of biomass burning aerosol: a modeling case study of the 2010 mega-fire event in Russia, Atmos. Chem. Phys., 15, 1326913297, doi:10.5194/acp-15-13269-2015, 2015.

Laing, J. R., Hee, J., and Jaffe, D. A.: Physical and Optical Properties of Aged Biomass Burning Aerosol from wildfires in Siberia and the western US at the Mt. Bachelor Observatory, in preparation, 2016.

Lee, K.: Change of particle size distribution during Brownian coagulation, J. Colloid Interf. Sci., 92, 315-325, doi:10.1016/00219797(83)90153-4, 1983.

Lee, L. A., Carslaw, K. S., Pringle, K. J., Mann, G. W., and Spracklen, D. V.: Emulation of a complex global aerosol model to quantify sensitivity to uncertain parameters, Atmos. Chem. Phys., 11, 12253-12273, doi:10.5194/acp-11-12253-2011, 2011.

Lee, L. A., Carslaw, K. S., Pringle, K. J., and Mann, G. W.: Mapping the uncertainty in global CCN using emulation, Atmos. Chem. Phys., 12, 9739-9751, doi:10.5194/acp-12-9739-2012, 2012.

Lee, L. A., Pringle, K. J., Reddington, C. L., Mann, G. W., Stier, P., Spracklen, D. V., Pierce, J. R., and Carslaw, K. S.: The magnitude and causes of uncertainty in global model simulations of cloud condensation nuclei, Atmos. Chem. Phys., 13, 8879-8914, doi:10.5194/acp-13-8879-2013, 2013.

Lee, S., Kim, H. K., Yan, B., Cobb, C. E., Hennigan, C., Nichols, S., Chamber, M., Edgerton, E. S., Jansen, J. J., Hu, Y., Zheng, M., Weber, R. J., and Russell, A. G.: Diagnosis of aged prescribed burning plumes impacting an urban area, Environ. Sci. Technol., 42, 1438-1444, 2008.

Levin, E. J. T., McMeeking, G. R., Carrico, C. M., Mack, L. E., Kreidenweis, S. M., Wold, C. E., Moosmüller, H., Arnott, W. P., Hao, W. M., Collett, J. L., and Malm, W. C.: Biomass burning smoke aerosol properties measured during Fire Laboratory at Missoula Experiments (FLAME), J. Geophys. Res., 115, D18210, doi:10.1029/2009JD013601, 2010.

Lonsdale, C. R., Stevens, R. G., Brock, C. A., Makar, P. A., Knipping, E. M., and Pierce, J. R.: The effect of coal-fired powerplant $\mathrm{SO}_{2}$ and $\mathrm{NO}_{x}$ control technologies on aerosol nucleation in the source plumes, Atmos. Chem. Phys., 12, 11519-11531, doi:10.5194/acp-12-11519-2012, 2012.

May, A. A., Levin, E. J. T., Hennigan, C. J., Riipinen, I., Lee, T., Collett, J. L., Jimenez, J. L., Kreidenweis, S. M., and Robinson, A. L.: Gas-particle partitioning of primary organic aerosol emissions: 3. Biomass burning, J. Geophys. Res.-Atmos., 118, 11327-11338, doi:10.1002/jgrd.50828, 2013. 
May, A. A., Lee, T., McMeeking, G. R., Akagi, S., Sullivan, A. P., Urbanski, S., Yokelson, R. J., and Kreidenweis, S. M.: Observations and analysis of organic aerosol evolution in some prescribed fire smoke plumes, Atmos. Chem. Phys., 15, 6323-6335, doi:10.5194/acp-15-6323-2015, 2015.

Mesinger, F., Dimego, G., Kalnay, E., Mitchell, K., Shafran, P. C., Ebisuzaki, W., Jović, D., Woollen, J., Rogers, E., Berbery, E. H., Ek, M. B., Fan, Y., Grumbine, R., Higgins, W., Li, H., Lin, Y., Manikin, G., Parrish, D., and Shi, W.: North American Regional Reanalysis: A long-term, consistent, high-resolution climate dataset for the North American domain, as a major improvement upon the earlier global reanalysis datasets in both resolutionand accuracy, B. Am. Meteorol. Soc., 87, 343-360, 2006.

Ortega, A. M., Day, D. A., Cubison, M. J., Brune, W. H., Bon, D., de Gouw, J. A., and Jimenez, J. L.: Secondary organic aerosol formation and primary organic aerosol oxidation from biomass-burning smoke in a flow reactor during FLAME-3, Atmos. Chem. Phys., 13, 11551-11571, doi:10.5194/acp-1311551-2013, 2013.

Petters, M. D., Carrico, C. M., Kreidenweis, S. M., Prenni, A. J., DeMott, P. J., Collett, J. L., and Moosmüller, H.: Cloud condensation nucleation activity of biomass burning aerosol, J. Geophys. Res., 114, D22205, doi:10.1029/2009JD012353, 2009.

Pierce, J. and Sakomoto, K.: SAM-TOMAS and GEM-SA emulator data, available at: http://hdl.handle.net/10217/173045, last access: 21 June 2016.

Pierce, J. R., Chen, K., and Adams, P. J.: Contribution of primary carbonaceous aerosol to cloud condensation nuclei: processes and uncertainties evaluated with a global aerosol microphysics model, Atmos. Chem. Phys., 7, 5447-5466, doi:10.5194/acp-75447-2007, 2007.

Pierce, J. R., Riipinen, I., Kulmala, M., Ehn, M., Petäjä, T., Junninen, H., Worsnop, D. R., and Donahue, N. M.: Quantification of the volatility of secondary organic compounds in ultrafine particles during nucleation events, Atmos. Chem. Phys., 11, 90199036, doi:10.5194/acp-11-9019-2011, 2011.

Reid, J. S., Koppmann, R., Eck, T. F., and Eleuterio, D. P.: A review of biomass burning emissions part II: intensive physical properties of biomass burning particles, Atmos. Chem. Phys., 5, 799825, doi:10.5194/acp-5-799-2005, 2005.

Reid, J. S., Hyer, E. J., Prins, E. M., Westphal, D. L., Zhang, J., Wang, J., Christopher, S. a., Curtis, C. a., Schmidt, C. C., Eleuterio, D. P., Richardson, K. a., and Hoffman, J. P.: Global Monitoring and Forecasting of Biomass-Burning Smoke: Description of and Lessons From the Fire Locating and Modeling of Burning Emissions (FLAMBE) Program, IEEE J. Sel. Top. Appl. Earth Obs. Remote Sens., 2, 144-162, doi:10.1109/JSTARS.2009.2027443, 2009.

Reid, S. and Hobbs, P. V.: Physical and optical properties of young smoke from individual biomass fires in Brazil, J. Geophys. Res., 103, 13-30, 1998.

Sakamoto, K. M., Allan, J. D., Coe, H., Taylor, J. W., Duck, T. J., and Pierce, J. R.: Aged boreal biomass-burning aerosol size distributions from BORTAS 2011, Atmos. Chem. Phys., 15, 16331646, doi:10.5194/acp-15-1633-2015, 2015.

Seinfeld, J. H. and Pandis, S. N.: Atmospheric Chemistry and Physics, Wiley, Hoboken, New Jersey, 2006.
Spracklen, D. V., Carslaw, K. S., Pöschl, U., Rap, A., and Forster, P. M.: Global cloud condensation nuclei influenced by carbonaceous combustion aerosol, Atmos. Chem. Phys., 11, 9067-9087, doi:10.5194/acp-11-9067-2011, 2011.

Stein, A. F., Draxler, R. R., Rolph, G. D., Stunder, B. J. B., Cohen, M. D., and Ngan, F.: NOAA's HYSPLIT Atmospheric Transport and Dispersion Modeling System, B. Am. Meteorol. Soc., 96, 2059-2077, doi:10.1175/BAMS-D-14-00110.1, 2015.

Stevens, R. G. and Pierce, J. R.: A parameterization of subgrid particle formation in sulfur-rich plumes for global- and regional-scale models, Atmos. Chem. Phys., 13, 12117-12133, doi:10.5194/acp-13-12117-2013, 2013.

Stevens, R. G., Pierce, J. R., Brock, C. A., Reed, M. K., Crawford, J. H., Holloway, J. S., Ryerson, T. B., Huey, L. G., and Nowak, J. B.: Nucleation and growth of sulfate aerosol in coal-fired power plant plumes: sensitivity to background aerosol and meteorology, Atmos. Chem. Phys., 12, 189-206, doi:10.5194/acp12-189-2012, 2012.

Stuart, G. S., Stevens, R. G., Partanen, A.-I., Jenkins, A. K. L., Korhonen, H., Forster, P. M., Spracklen, D. V., and Pierce, J. R.: Reduced efficacy of marine cloud brightening geoengineering due to in-plume aerosol coagulation: parameterization and global implications, Atmos. Chem. Phys., 13, 10385-10396, doi:10.5194/acp-13-10385-2013, 2013.

Vakkari, V., Kerminen, V.-M., Beukes, J. P., Tiitta, P., van Zyl, P. G., Josipovic, M., Venter, A. D., Jaars, K., Worsnop, D. R., Kulmala, M., and Laakso, L.: Rapid changes in biomass burning aerosols by atmospheric oxidation, Geophys. Res. Lett., 26442651, doi:10.1002/2014GL059396, 2014.

van der Werf, G. R., Randerson, J. T., Giglio, L., Collatz, G. J., Mu, M., Kasibhatla, P. S., Morton, D. C., DeFries, R. S., Jin, Y., and van Leeuwen, T. T.: Global fire emissions and the contribution of deforestation, savanna, forest, agricultural, and peat fires (19972009), Atmos. Chem. Phys., 10, 11707-11735, doi:10.5194/acp10-11707-2010, 2010.

Whitby, E., McMurry, P., Shankar, U., and Binkowski, F. S.: Modal Aerosol Dynamics Modeling, Tech. rep., Office of research and development US Environmental Protection Agency, 1991.

Wiedinmyer, C., Akagi, S. K., Yokelson, R. J., Emmons, L. K., AlSaadi, J. A., Orlando, J. J., and Soja, A. J.: The Fire INventory from NCAR (FINN): a high resolution global model to estimate the emissions from open burning, Geosci. Model Dev., 4, 625641, doi:10.5194/gmd-4-625-2011, 2011.

Yokelson, R. J., Crounse, J. D., DeCarlo, P. F., Karl, T., Urbanski, S., Atlas, E., Campos, T., Shinozuka, Y., Kapustin, V., Clarke, A. D., Weinheimer, A., Knapp, D. J., Montzka, D. D., Holloway, J., Weibring, P., Flocke, F., Zheng, W., Toohey, D., Wennberg, P. O., Wiedinmyer, C., Mauldin, L., Fried, A., Richter, D., Walega, J., Jimenez, J. L., Adachi, K., Buseck, P. R., Hall, S. R., and Shetter, R.: Emissions from biomass burning in the Yucatan, Atmos. Chem. Phys., 9, 5785-5812, doi:10.5194/acp-9-5785-2009, 2009. 